\title{
Overview of the development of the Aerosol Loading Interface for Cloud microphysics In Simulation (ALICIS)
}

\author{
Takamichi Iguchi ${ }^{1,2^{*}}$, In-Jin $\mathrm{Choi}^{3}$, Yousuke Sato ${ }^{4}$, Kentaroh Suzuki ${ }^{5}$ and Teruyuki Nakajima ${ }^{6}$
}

\begin{abstract}
This review summarizes the scientific background of and past/prospective update strategies for the development of the Aerosol Loading Interface for Cloud microphysics In Simulation (ALICIS). ALICIS provides a novel approach for coupling downscaled mesoscale cloud-resolving simulations to large-scale aerosol-transport simulations. Realistic aerosol loading, including spatio-temporal aerosol variations and particle-size spectra, is implemented in the cloudresolving simulations. Prior studies employing ALICIS have demonstrated how the interface introduction significantly improves the reproducibility of the simulated microphysical cloud structure through better representation of aerosol effects on cloud.
\end{abstract}

Keywords: Cloud microphysics, Cloud and aerosol, Regional modeling, Dynamical downscaling

\section{Review}

Introduction

Aerosol effects on cloud in atmospheric models

The coexistence of the three phases of hydrogen monoxide is, within the solar system, unique to the Earth's atmosphere. The liquid and solid phases in the atmosphere (i.e., cloud and precipitation) play critical roles in determining the Earth's radiation balance and hydrological cycle by driving considerable changes in the atmospheric hydrometeor distribution and characteristics. The hydrometeor behavior is controlled by various factors, not limited to phase changes affected by temperature, dry-air and vapor pressure, advection by background winds, and gravitational falling.

Particulate matter that is dispersed colloidally with a variety of the particle sizes, shapes, and chemical components in the Earth's atmosphere is referred to as aerosol. Aerosol particles are closely related to the liquid and solid particles making up clouds and precipitation; they are not only necessary for the nucleation process of hydrometeor particles but are also a source of impurities in these

\footnotetext{
* Correspondence: takamichi.iguchi@nasa.gov

${ }^{1}$ Earth System Science Interdisciplinary Center, University of Maryland, College Park, MD, USA

${ }^{2}$ Code 612 NASA Goddard Space Flight Center, Greenbelt, MD, USA Full list of author information is available at the end of the article
}

particles. To date, the aerosol influence on cloud has been investigated in a number of ways, from the perspectives of weather and climate research, as well as in the context of weather modification and geo-engineering, starting from a series of studies by Twomey and Squires who examined microphysical cloud structure under various airmass conditions using in situ aircraft measurements in the 1950s and 1960s (e.g., Squires 1956). A well-known example demonstrating the effects of aerosol is that of the systematic difference in microphysical properties between continental and oceanic clouds. Continental clouds generally have a smaller mean particle size and a higher particle number concentration than oceanic clouds. These differences are attributed to the disparity in aerosol concentration and characteristics between the regions.

Aerosol was not represented explicitly in most numerical models of the Earth's atmosphere on global or regional scales until the 1990s, despite its significance for clouds and climate. This was due in part to the fact the models were generally aimed at analyses of the atmosphere's dynamical structure and at land-surface rainfall predictions. Researchers thus considered aerosol unimportant in the basic framework of atmospheric models, because it had no direct influence on mass or energy conservation in the atmosphere and its fluid dynamics. In addition, computational resources were insufficient to explicitly include

\section{Springer}


aerosol. Aerosol effects on cloud were thus tacitly included in the models in the form of parametrizations consisting of empirical equations. For example, saturation adjustment (Soong and Ogura 1973; Tao et al. 1989) is a reasonable assumption for calculations of the nucleation of cloud droplets and their condensation growth from water vapor. Even though the presence of aerosol is a requirement for the droplets' nucleation process, the details are not important because of the wealth of aerosol particles that can be activated as cloud condensation nuclei $(\mathrm{CCN})$ in the troposphere.

In the 1990s and 2000s, increasing interest in aerosol brought the issue under consideration even in the context of atmospheric modeling approaches. The most significant turning point was the recognition that aerosol might counter the anthropogenic gases that cause global warming through their greenhouse effect. Tropospheric aerosol particles have a direct impact on the Earth's radiative balance through the scattering and absorption of short- and longwave radiation (i.e., aerosol direct radiative forcing). In addition, aerosol particles have an indirect influence on the Earth's radiative balance through altering optical cloud properties by serving as $\mathrm{CCN}$ (i.e., aerosol indirect radiative forcing). An increase in the concentration of tropospheric aerosol particles may enhance cloud reflectance for solar irradiance as a result of the increased droplet number concentration and reduced droplet size for a fixed liquid water path (Twomey 1974, 1977; Twomey et al. 1984). On the other hand, a decrease in droplet size may inhibit droplet growth through collisional coagulation during warmrain formation; this effect has an influence on the Earth's cloud coverage through altering cloud lifetimes owing to the suppression of rain formation (Albrecht 1989).

Including the aerosol influence proved necessary in assessments of the Earth's radiation balance and, consequently, the surface air temperature, not only in the future but also in the past. Simultaneously, researchers have become gradually more interested in changes in the precipitation amount through modification of cloud dynamical/microphysical structures by anthropogenic factors related to aerosol (Levin and Cotton 2008; Tao et al. 2012). Many numerical models have been developed competitively to represent aerosol-cloud interactions and their impacts on climate and weather phenomena on global and regional scales. In addition, remote and in situ measurements have been conducted worldwide to provide chances for modelers to justify their results. Satellite measurements have produced global projections of the distribution and characteristics of aerosol and clouds on the basis of measurements of their optical properties through spaceborne remote sensors (e.g., Nakajima et al. 2001; Rosenfeld et al. 2014). Continuous observations of aerosol by ground-based networks allow researchers to trace long-term transitions in their characteristics (e.g., Aerosol Robotic Network (AERONET) Holben et al. 1998; US Department of Energy (DOE), atmospheric radiation measurement (ARM) Stokes and Schwartz 1994). Many intensive field campaigns have also been conducted to produce comprehensive views of aerosolcloud interaction by coupling observation results obtained from spaceborne satellites with ground-based, seaborne, and airborne instruments, as well as model simulations (e.g., INDian Ocean Experiment (INDOEX) Ramanathan et al. 2001; Asian Pacific Regional Aerosol Characterization Experiment (ACE-Asia) Huebert et al. 2003; Atmospheric Brown Clouds (ABC) Nakajima et al. 2007; Ramanathan et al. 2007; and Distributed Regional Aerosol Gridded Observation Networks (DRAGON) Eck et al. 2012).

\section{Modeling approaches to aerosol and its activation in droplet nucleation}

An essential physical process connecting aerosol with cloud is the nucleation of hydrometeor particles. All aerosol particles that can potentially be activated as nuclei of cloud droplets are referred to as condensation nuclei $(\mathrm{CN})$. $\mathrm{CCN}$ are a subset of $\mathrm{CN}$; they can be activated to initiate droplet formation at the low supersaturation observed in the troposphere. In contrast, ice-forming nuclei (IN) are defined as aerosol particles that act as the base of the deposition nucleation of cloud-ice particles or the heterogeneous freezing of supercooled droplets. At present, our knowledge of IN is less complete than that of CCN because of insufficient availability of measurements and experimental data to model the complicated ice-nucleation process (Pruppacher and Klett 1997).

A fundamental theory about $\mathrm{CCN}$ activation is summarized in a chart relating the relationship between the vapor saturation ratio and the equilibrium droplet size formed in CCN (Köhler 1936, Appendix 1). CN size distribution spectra, as well as ambient supersaturation and temperature, are essential factors in determining the droplet nucleation process. Several additional factors have a potential impact on the balance of the vapor saturation ratio and the equilibrium droplet size under more complex assumptions, other than the basic Köhler theory, such as changes in the amount of dissolving solutes in a droplet, temperature variations through latent heating/cooling by vapor condensation and evaporation, and the existence of insoluble and multiple soluble chemical components in impacted $\mathrm{CN}$.

The question of how to numerically handle the two critical components (i.e., the size distribution spectra of aerosol particles and ambient supersaturation) is an important issue in the representation of the droplet nucleation process in cloud microphysics schemes. Existing approaches are generally categorized into the following four types, according 
to the temporal and spatial resolutions, and the aerosol representation in the models: (i) the use of supersaturation and aerosol size distribution spectra explicitly predicted for each spatial grid point; (ii) the use of parametrization involving predicted grid-scale supersaturation or updraft wind velocity, as well as the mass and/or number concentration of aerosol particles; (iii) the use of parametrization including the diagnosed maximum supersaturation or updraft wind velocity instead of predicted grid-scale values, as well as the mass and/or number concentration of aerosol particles; and (iv) the use of parametrization that implicitly assumes the presence of aerosol.

The first approach has been employed in a limited number of cloud-resolving models (CRMs) that aim at accurate calculation of cloud microphysics (e.g., Kogan 1991; Chen and Lamb 1994; Feingold et al. 1999; Khain et al. 2000; Geresdi and Rasmussen 2005; Lynn et al. 2005a; Kuba and Fujiyoshi 2006; Suzuki et al. 2006, 2010; Li et al. 2008; Shima et al. 2009; Misumi et al. 2010; Xue et al. 2010; Fan et al. 2012). The so-called sectional representation (e.g., Abdul-Razzak and Ghan 2002) is employed to numerically handle aerosol size distribution spectra in most of these models. Köhler theory is used to directly calculate the $\mathrm{CCN}$ number concentration and, consequently, the increased cloud droplet number concentration (CDNC) from the predicted aerosol size distribution spectra and supersaturation. Consumption of aerosol particles through the nucleation process is explicitly represented in the size distribution spectrum predicted. Miscellaneous aerosol types are often simplified to monotype $\mathrm{CN}$ to reduce the complexity. These CRMs sometimes lack a grid structure of full three-dimensional Cartesian coordinates, i.e., they may have only a two- or one-dimensional grid structure. Large computational resources are required to ensure sufficient accuracy to explicitly resolve aerosol size distribution spectra. In addition, very fine grid spacings in both time and space are required to represent minute variations in supersaturation. Such CRMs are generally employed to simulate idealized and simplified clouds to investigate the basic mechanisms of cloud and precipitation formation, and to discuss the sensitivity to various factors, including aerosol concentration. Typical size distribution forms of aerosol particles are often prescribed using reference measurement data.

The second approach is employed in high-resolution regional models that can be used for aerosol-cloud interaction studies based on idealized experiments or case studies. Generalized aerosol size distribution functions are usually assumed instead of their explicitly resolved spectra. The total or species-distinguished aerosol concentration is explicitly predicted in bulk-moment forms in some models (e.g., Hashino and Tripori 2007; Muhlbauer and Lohmann 2009; Onishi and Takahashi
2012; Saleeby and van den Heever 2013; Thompson and Eidhammer 2014), whereas the aerosol concentration is not predicted but tacitly parametrized in some models (e.g., Rasmussen et al. 2002; Seifert and Beheng 2006; Morrison and Grabowski 2007; Seiki and Nakajima 2014; Seiki et al. 2015). In most of these models, the activated $\mathrm{CCN}$ number concentration is parametrized on the basis of the basic Köhler theory, using the predicted supersaturation or vertical wind velocity. An empirical parametrization was suggested by Twomey (1959a, $1959 \mathrm{~b})$ to calculate the activated CCN number concentration from the predicted supersaturation or vertical wind velocity and prescribed coefficients representing the ambient aerosol loading. A more generalized parametrization was proposed by Abdul-Razzak et al. (1998), which combines Twomey's parametrization with a lognormal representation of the aerosol size distribution (Ghan et al. 1993); these authors also extended the parameterization to cases including multiple externally mixed aerosol types (Abdul-Razzak and Ghan 2000). On the other hand, Saleeby and Cotton (2004) proposed the use of pre-calculated lookup tables through Lagrangian parcel model calculations instead of empirical parametrizations; aerosol size distribution spectra are explicitly represented using a sectional approach in the parcel model. The lookup tables are used to calculate the proportion of aerosol particles activated for droplet nucleation by referring to the vertical wind velocity predicted in their main model framework.

The third approach is used in most global or coarseresolution regional models for studies of aerosol-cloud interactions, even on a climatic scale (e.g., Storelvmo et al. 2006, 2008; Lohmann et al. 2007; Morrison and Gettelman 2008; Suzuki et al. 2008; Takemura et al. 2009; Wang et al. 2011; Wang et al. 2013; Park et al. 2014; Shi et al. 2014). Supersaturation and the vertical wind velocity cannot be resolved well on model grid points with coarse intervals. Saturation adjustment approaches are necessarily employed in the calculation of phase changes between vapor and cloud water/ice. The approach used to introduce aerosol-to-cloud effects is significantly different among models according to the type of bulk cloud microphysics employed. Models using double-moment bulk cloud microphysics generally employ empirical parametrizations (e.g., Abdul-Razzak et al. 1998; AbdulRazzak and Ghan 2000) to obtain the relationship between the aerosol number concentration and CDNC. Since the grid-scale vertical velocity is not a suitable input into the parametrizations, diagnostic variables (e.g., turbulent kinetic energy) are often included in modified parametrizations to determine the activated $\mathrm{CCN}$ number concentration through diagnosis of the maxima of the vertical wind velocity and supersaturation (e.g., Morrison et al. 2005). In contrast, single-moment bulk cloud 
microphysics cannot directly incorporate the activated $\mathrm{CCN}$ number concentration into the microphysics calculations in the form of a CDNC change. Diagnosed $\mathrm{CDNC}$ can be included in the calculation of the autoconversion rate from cloud to rain to represent the ambient CN effect on clouds (e.g., Liu and Daum 2004).

The fourth approach is adopted in model simulations on any scale. Since aerosol particles are necessary for the nucleation of cloud particles, the presence of aerosol particles is always assumed in cloud microphysics in a steady form. Explicit representation of aerosol and its effect on cloud may cause excess computational costs and uncertainties in regular operational runs for shorttime weather forecasting. Speedy and stable simulation is important in these runs. Even coarse parametrizations based on empirical formulas work reasonably well for such short-time simulations where aerosol loading has little direct influence and minor feedback on the prognostic variables.

\section{Solutions to the problem related to aerosol-to-cloud modeling}

The best approach to accurately simulating aerosol-tocloud effects is obviously the first option discussed in "Modeling approaches to aerosol and its activation in droplet nucleation", i.e., using the explicitly predicted supersaturation and aerosol size distribution. However, predictions of the two components under realistic conditions are contradictory problems in a single-model framework because of scale gaps between aerosol and cloud. A small computational domain is preferable to define the grid spacing as finely as possible to represent minor variations in supersaturation. In contrast, a large computational domain is preferred to strictly predict transitions in the aerosol concentration and size distribution from sources of aerosol-particle formation. The limited capability of present computational resources places results in insufficient domain size and grid spacing in a single-model framework.

Several methods can be employed to solve the scale dilemma in aerosol-to-cloud modeling in the present computing environment. Thompson and Eidhammer (2014) used monthly aerosol climatology data as input into their Weather Research and Forecasting (WRF) model simulations (Skamarock et al. 2005). The aerosol climatology data were derived from multiannual global aerosol model simulations using the NASA Goddard Earth Observing System model coupled with the Goddard Chemistry Aerosol Radiation and Transport model (GEOS-GOCART, Ginoux et al. 2001; Chin et al. 2002; Colarco et al. 2010). The climatological data were composed of mass-mixing ratios of the five aerosol species with $0.5^{\circ} \times 1.25^{\circ}$ horizontal grid spacing. The mass-mixing ratios were converted into two bulk number concentrations. One is the number concentration of simplified hygroscopic aerosol particles based on combining all aerosol species except for dust and black carbon. The second is that of simplified icenucleating particles based on the accumulation of dust particles with diameters larger than $0.5 \mu \mathrm{m}$. Both number concentrations were explicitly predicted in the WRF model simulations as tracers affected by interactions with hydrometeors and emission from the land surface. The predicted aerosol number concentrations were used in calculating the activation process of aerosol particles in the bulk cloud microphysics scheme. Aerosol activation (i.e., cloud droplet nucleation) was calculated using a method employing pre-calculated lookup tables (e.g., Saleeby and Cotton 2004). Cloud-ice nucleation and heterogeneous freezing of supercooled droplets were calculated using the parametrizations of Bigg (1953), Koop et al. (2000), Phillips et al. (2008), and DeMott et al. (2010).

Shi et al. (2014) used aerosol and chemical-transport model simulations as a tool to provide a realistically diagnosed aerosol field for their cloud microphysics calculation in the main model framework with the same domain configuration. They incorporated the following two individual models off-line: the GOCART solomodule version of the WRF coupled with chemistry (WRF-Chem; Grell et al. 2005), and the National Aeronautics and Space Administration (NASA) Unified WRF (NU-WRF; Peters-Lidard et al. 2015). The activated CCN number concentration in the NU-WRF simulation was diagnosed based on the air temperature and supersaturation on the NU-WRF side, and the mass concentration of multiple aerosol species on the WRF-Chem GOCART side. The diagnosed CCN number concentration was used to modulate the autoconversion rate from cloud to rain through CDNC diagnosis in the framework of the single-moment bulk cloud microphysics in the NU-WRF simulation.

Another compromise adopted to address this problem was suggested by Iguchi et al. (2008; hereafter IG08). Their approach was based on dynamical downscaling of realistic aerosol fields from large-scale aerosol (and chemical) transport model simulations to small-scale CRM simulations. The basic numerical framework of aerosol downscaling was similar to that of dynamical downscaling for standard prognostic variables such as wind velocity, temperature, and vapor-mixing ratio. Initial and time-variant aerosol boundary conditions were prepared using four-dimensional output from the largescale simulation. However, aerosol size distribution spectra were incompletely resolved in the large-scale aerosol transport model. This deficiency might be problematic for accurate calculation of the activated $\mathrm{CCN}$ number concentration on the basis of Köhler theory on the CRM side. To deal with this problem in a reasonable manner, 
the authors proposed the use of an additional intermediate module. The intermediate aerosol loading module complemented the information of the aerosol size distribution spectra in the dynamical downscaling framework. The aerosol size distribution spectra and their total number/ mass concentrations should be as realistic as possible, such as those observed at times and locations pertaining to the simulations.

The objective of this review is to summarize our development activities and prospective update strategies for the aerosol loading interface since the publication of IG08. The interface connects small-scale CRM simulations to large-scale aerosol transport simulations in a dynamical downscaling framework and complements information about aerosol size distribution spectra. This interface is currently undergoing development in order to couple it with regional models, including a detailed cloud microphysical scheme, referred to as spectral-bin microphysics (SBM; e.g., Khain et al. 2015). Since this paper aims at reviewing the aerosol loading interface in detail, detailed descriptions of SBM are not included. Such descriptions can be found in Khain et al. $(2000,2015)$, among others.

\section{Description of ALICIS \\ Brief overview}

Our aerosol loading module is referred to as the Aerosol Loading Interface for Cloud microphysics In Simulation (ALICIS). Figure 1 provides a schematic illustration of how ALICIS works as an intermediate module between largescale aerosol transport models and regional-scale CRMs. So far, this interface has been employed in the framework connecting global-scale simulations using the spectral radiation transport model for aerosol species (SPRINTARS; e.g.,
Takemura et al. 2000) with regional-scale simulations using the Japan Meteorological Agency Non-Hydrostatic Model (JMA-NHM; Saito et al. 2006) coupled with SBM (IG08). The SBM scheme originates from the corresponding part of the Hebrew University Cloud Model (HUCM; e.g., Khain et al. 2000). ALICIS was first published by IG08 and subsequently updated by Sato et al. (2012; hereafter SA12) and Choi et al. (2014; hereafter CH14).

\section{$\mathrm{CN}$ modeling in the original HUCM}

The representation of aerosol in the original HUCM is significantly simplified for idealized CRM simulations (e.g., Khain et al. 1999). The $\mathrm{CN}$ size distribution spectrum for a single chemical component is calculated as prognostic variables for each of the model's spatial grid points. The chemical composition of $\mathrm{CN}$ is assumed to consist of pure ammonium sulfate. The $\mathrm{CN}$ particle shape is assumed to be completely spherical. The size distribution spectrum is approximated by 33 discrete size bins, covering a particle radius ranging from $1.23 \times 10^{-3}$ to $2 \mu \mathrm{m}$. The representative particle radius of each $\mathrm{CN}$ size bin is defined as follows. The $\mathrm{CN}$ particle mass of the maximum size bin (i.e., the 33rd bin) is assumed to be identical to the particle mass of the smallest droplet size bin; the smallest droplet radius is assumed to be $2 \mu \mathrm{m}$. The $\mathrm{CN}$ particle mass of each size bin is determined by doubling the mass bins; that is, a series of $\mathrm{CN}$ bins are characterized in the form of a geometric progression of particle masses with a ratio of 2 between subsequent bins. The $\mathrm{CN}$ particle radius of each size bin is tied to the particle mass of the bin and the $\mathrm{CN}$ particle density.

The initial CN size distribution spectrum in the HUCM is determined using the Köhler equation (Eq. 11) and

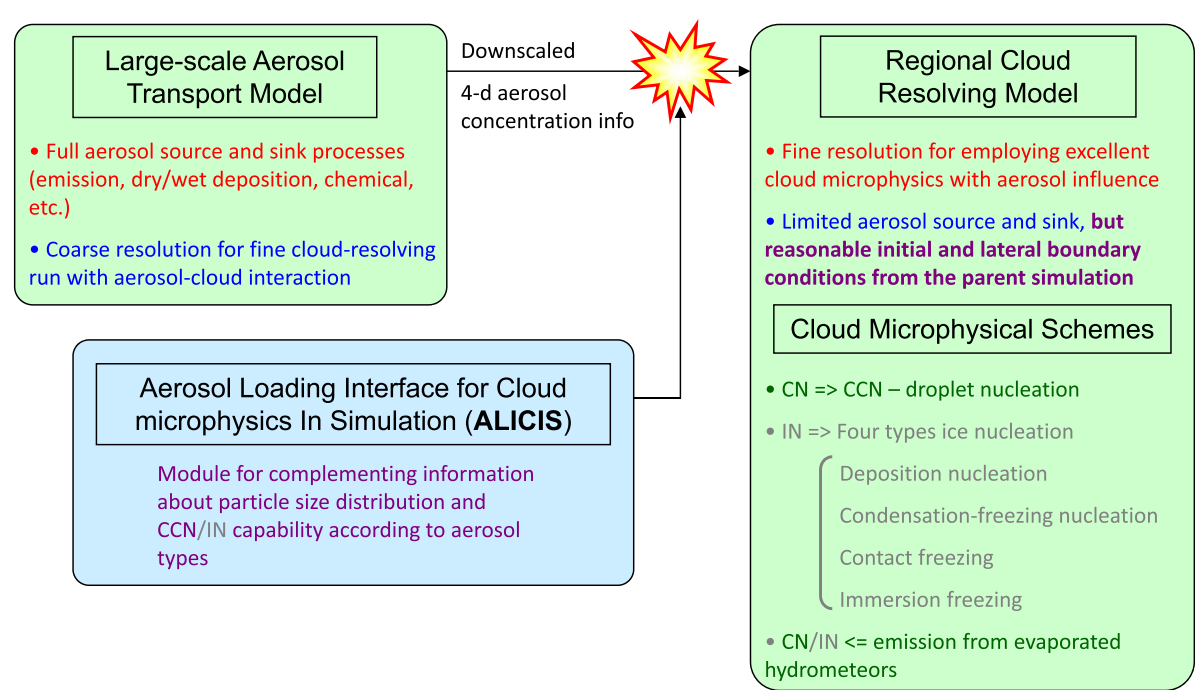

Fig. 1 Conceptual diagram of the coupling framework between a large-scale aerosol transport model and a regional-scale cloud resolving model using the ALICIS module. Gray components have not yet been implemented but will be included in future updates 
Twomey's empirical parametrization described by $N_{\mathrm{CCN}}=$ $N_{0} S^{k}$. Here, $N_{\mathrm{CCN}}$ is the number concentration of CCN activated at supersaturation $S$, and $N_{0}$ and $k$ are environment-dependent coefficients (e.g., Twomey 1959a, 1959b). The following equation for the $\mathrm{CN}$ number density function can be obtained by coupling both equations (Khain et al. 2000):

$$
\frac{\mathrm{d} N_{\mathrm{CN}}}{\mathrm{d}\left(\ln r_{\mathrm{CN}}\right)}=1.5 N_{0} k\left(\frac{4 A^{3}}{27 B r_{\mathrm{CN}}}\right)^{1.5 k}
$$

where $A$ and $B$ are calculated from Eq. 8 for a temperature of $288.15 \mathrm{~K}$, and the molecular weight, the van ' $t$ Hoff factor, and the $\mathrm{CN}$ particle density are identical to those of a typical ammonium sulfate aerosol particle. The spectral shape of the initial $\mathrm{CN}$ size distribution is common to all spatial model grid points. The initial spatial distribution is vertically inhomogeneous, since the $\mathrm{CN}$ number density function decreases exponentially with a scale height of $2 \mathrm{~km}$ above an altitude of $2 \mathrm{~km}$ (Khain and Sednev 1996). CN particles with radii larger than $0.6 \mu \mathrm{m}$ are eliminated from the size distribution spectrum in standard simulations to prevent artificially rapid formation of large droplets at the initial simulation stage.

The governing equation of the number density concentration in each CN bin (Eq. 3.4 of Khain and Sednev 1996) is calculated numerically for all model grid points and each time step. Gravitational sedimentation of $\mathrm{CN}$ particles is neglected. $\mathrm{CN}$ production in the atmosphere or on the terrain surface is ignored. No direct $\mathrm{CN}$ source term is assumed. The $\mathrm{CN}$ sink is limited to consumption through the droplet nucleation process. Scattering and absorption of short- and longwave radiative fluxes by $\mathrm{CN}$ particles are not included, because no radiation process is calculated in the HUCM. A flat horizontal gradient of the $\mathrm{CN}$ number density concentration is assumed at the model's lateral boundaries; the $\mathrm{CN}$ size distribution spectra are thus horizontally constant near the lateral boundaries. Consequently, $\mathrm{CN}$ consumed within the simulation domain is replenished by advection from the lateral boundaries.

The microphysical process of $\mathrm{CN}$ is limited to activation of droplet nucleation. The process is calculated on the basis of the following approach. If the predicted supersaturation at a grid point is positive, the critical radius of $\mathrm{CCN}$ is calculated based on Eq. 11 using supersaturation and the air temperature. All $\mathrm{CN}$ larger than the critical radius are immediately activated and converted into cloud droplets, with their corresponding radii calculated using Eq. 10. Hygroscopic growth of $\mathrm{CN}$ is neglected.

\section{An early version of ALICIS: Iguchi et al. (2008)}

Recently, regional models using SBM have been widely applied, even to realistic simulations resolving clouds.
However, most studies have employed a similarly coarse approach to the CN representation (Lynn et al. 2005a, 2005b; Khain et al. 2010; Fan et al. 2012; Iguchi et al. 2012a, 2012b, 2014). Such an approach may be insufficient in realistic simulations, because in reality, the spatial distribution of aerosol particles is inhomogeneous and variable. The environment-dependent parameters in Eq. $1, N_{0}$ and $k$, are determined on the basis of limited reference observations (Pruppacher and Klett 1997). Substitution of arbitrary values for those parameters causes large uncertainties in determining the $\mathrm{CN}$ concentration and size distribution spectra that should be consistent with their real counterparts. In particular, the uncertainties may be increased under conditions where anthropogenic pollution has a large impact on the aerosol distribution. Aerosol-cloud interaction is of great interest as a research problem under such conditions. In addition, the simplified vertical $\mathrm{CN}$ distribution may be problematic. The vertical $\mathrm{CN}$ profile assumed in the HUCM is based on a typical observed profile of the vertical aerosol distribution. However, severe aerosol contamination is sometimes observed even in the middle troposphere (Marenco et al. 2014); such highly concentrated aerosol is transported from distant intensive sources through lifting by convection and it even has a significant impact on the local cloud properties as well as on the radiation balance.

IG08 developed the aerosol loading module ALICIS to overcome the deficiencies in $\mathrm{CN}$ modeling associated with the original HUCM. The module provides inhomogeneous initial $\mathrm{CN}$ and time-variant lateral boundary conditions with a specified particle-size distribution through a dynamical downscaling approach using output from global aerosol transport simulations of SPRINTARS (e.g., Takemura et al. 2000). The SPRINTARS model includes the five types of tropospheric aerosol, i.e., organic carbonaceous, black carbonaceous, soil dust, sulfate, and sea salt. Aerosol mass-mixing ratios are predicted in the framework of the atmospheric general circulation model (AGCM). Aerosol particle size spectra are incompletely resolved in SPRINTARS.

Aerosol transport simulations using the SPRINTARS model have been validated in various ways. For example, the simulated aerosol optical thickness and Ångström exponents have been compared with those retrieved from the space-borne Advanced Very High Resolution Radiometer (AVHRR) measurements on a global scale (Takemura et al. 2000); these authors also evaluated the surface aerosol concentration at multiple global locations by comparison with those estimated from optical measurements of the AERONET network. The singlescattering albedo of simulated aerosol was also validated using AERONET data (Takemura et al. 2002). An aerosol data assimilation system has been developed on the 
basis of a four-dimensional variational data assimilation method (Yumimoto and Takemura 2013). The vertical aerosol distribution was validated through a comparison of the aerosol extinction with lidar measurements at several locations in Japan (Goto et al. 2015). In addition, the SPRINTARS model is included in the Aerosol Comparisons between Observations and Models (AEROCOM) project (e.g., Kinne et al. 2006). Model performance has been evaluated by comparing the global modeling outcomes of numerous aerosol modules.

IG08 determined the $\mathrm{CN}$ size distribution spectrum of the initial and time-variant lateral boundary conditions in their nested model simulations through the following process. Among the five types of tropospheric aerosol, organic carbonaceous, sulfate, and sea salt aerosol particles are assumed to be $\mathrm{CN}$ activatable as $\mathrm{CCN}$. Bulk number concentrations of the three types of aerosol in SPRINTARS are calculated based on the predicted mass-mixing ratios for the grid points of the global simulation under the assumption that all aerosol particles are dry. The calculated bulk number concentrations are then temporally and spatially interpolated at the grid points of the simulation domain of the nested model. The interpolated bulk number concentrations are converted into aerosol size distribution spectra at each grid point. The conversion employs different built-in size distribution functions, according to aerosol type. Finally, accumulating the three-type aerosol size spectra yields the $\mathrm{CN}$ size distribution spectrum at a given grid point for the initial and boundary conditions.

The particle size distribution of organic carbonaceous aerosol is assumed to be a lognormal function with a single mode. The corresponding fraction of organic carbonaceous aerosol in the $\mathrm{CN}$ size distribution spectrum is given in units of the number density concentration,

$$
\frac{\mathrm{d} N_{\mathrm{CN}(\mathrm{OC})}}{\mathrm{d}\left(\ln r_{\mathrm{CN}}\right)}=\frac{N_{\mathrm{b}(\mathrm{OC})}}{\sqrt{2 \pi} \sigma_{\mathrm{OC}}} \exp \left[-\frac{1}{2}\left\{\frac{\ln \left(B_{\mathrm{CN}}^{1 / 3} / B_{\mathrm{OC}}^{1 / 3} \cdot r_{\mathrm{CN}} / r_{\mathrm{m}(\mathrm{OC})}\right)}{\sigma_{\mathrm{OC}}}\right\}^{2}\right],
$$

where $N_{\mathrm{b}}$ is the bulk aerosol number concentration of the SPRINTARS simulation, and $r_{\mathrm{m}}$ and $\sigma$ are the mode radius and the standard deviation of the lognormal aerosol size distribution, respectively. The subscripts, $\mathrm{CN}$ and $\mathrm{OC}$, distinguish the variables pertaining to $\mathrm{CN}$ and organic carbonaceous aerosol, respectively; $r_{\mathrm{m}(\mathrm{OC})}=0.1 \mu \mathrm{m}$ and $\sigma_{\mathrm{OC}}=1.8$ is assumed. Note that Eq. 2 applies the adjustment of the difference in the $B$ coefficients (Eq. 8) between organic carbonaceous aerosol and $\mathrm{CN}$ with a certain soluble component.

Sulfate aerosol is also assumed to have a single-mode lognormal particle size distribution. The corresponding portion of the sulfate aerosol in the $\mathrm{CN}$ size distribution spectrum is also given by Eq. 2 in units of the number density concentration, but for parameters typical of sulfate aerosol; $r_{m}=0.0695 \mu \mathrm{m}$ and $\sigma=2.03$ is assumed.

The particle size distribution function of sea salt aerosol is assumed to be a power law. The corresponding fraction of sea salt aerosol in the $\mathrm{CN}$ number density concentration is given by

$$
\frac{\mathrm{d} N_{\mathrm{CN}(\mathrm{SA})}}{\mathrm{d}\left(\ln r_{\mathrm{CN}}\right)}=1.5 N_{\mathrm{b}(\mathrm{SA})} k\left(\frac{B_{\mathrm{SA}}}{B_{\mathrm{CN}}} \frac{r_{\mathrm{m}(\mathrm{SA})}}{r_{\mathrm{CN}}^{3}}\right)^{k},
$$

where $r_{\mathrm{m}(\mathrm{SA})}=0.1 \mu \mathrm{m}$ and $k=0.6$ is assumed. The subscript SA denotes sea salt aerosol. This equation also includes adjustment of the difference in the $B$ coefficient between $\mathrm{CN}$ and sea salt aerosol.

In the version of ALICIS presented here, the $\mathrm{CN}$ size spectrum is discretely approximated by 13 size bins with a radius ranging from $10^{-3}$ to $1 \mu \mathrm{m}$. The use of a small number of $\mathrm{CN}$ bins compared with the 33 bins in the original HUCM yields improved computational efficiency. The $\mathrm{CN}$ concentration in each bin is numerically computed every time step, using almost the same governing equations as the standard scalar tracers.

The chemical component of $\mathrm{CN}$ in the nested model can be arbitrarily determined by substituting a proper, corresponding value into the $B$ coefficient of $\mathrm{CN}$ in the conversion equations (Eqs. 2 and 3). No microphysical processes causing a change in the $\mathrm{CN}$ size spectra are assumed, except for activation to droplet nucleation. Droplet nucleation is calculated using the same approach as that employed in the original HUCM; the value of the $B$ coefficient of $\mathrm{CN}$ in Eqs. 2 and 3 is substituted into Eqs. 10 and 11 to determine the critical $\mathrm{CCN}$ radius and the corresponding radius of the generated cloud droplet. Although atmospheric radiation is calculated in the nested model, absorption and scattering of the radiative fluxes by $\mathrm{CN}$ are not included at present. The reason for this is that the optical properties of each aerosol species are eliminated once the multiple aerosol types have been bundled into standardized $\mathrm{CN}$. In addition, the other two types of aerosol (i.e., black carbonaceous and dust aerosol) are not included in the nested model, so that this version of ALICIS has a limited capability to simulate direct aerosol effects on atmospheric radiation.

IG08 demonstrated the validity and effectiveness of the aerosol loading module in model simulations of two precipitation events observed during the 3rd Experiment of the Asian Atmospheric Particulate Environment Change Studies (APEX-E3). First, vertical profiles of the CCN number concentration in the nested model simulations were evaluated in direct comparison with those acquired by aircraft in situ measurements. The measurement 
methods of the $\mathrm{CCN}$ number concentration using a $\mathrm{CCN}$ counter were summarized by Ishizaka (2004) and Adhikari et al. (2005); some additional detailed information about the measurements on the event days can also be found in IG08. Figure 2 compares the results for the two individual cases. The simulations reproduced the observed $\mathrm{CCN}$ concentration profiles reasonably well. In the April 2 case (Fig. 2a), the observed CCN concentration ranged from approximately several tens to close to $1000 / \mathrm{cm}^{3}$. The observed concentration decreased a little with increasing altitude. The three-type simulated $\mathrm{CCN}$ concentrations ranged from approximately 100 to $1000 \mathrm{~cm}^{-3}$ at heights of up to $5500 \mathrm{~m}$; the small decrease with increasing altitude was generally reproduced. In the April 8 case (Fig. 2b), the observed CCN concentration was approximately $1000 \mathrm{~cm}$ ${ }^{-3}$ at heights below $1000 \mathrm{~m}$, which decreased with increasing altitude to roughly $100 \mathrm{~cm}^{-3}$ at $3000 \mathrm{~m}$. The vertical profiles of the simulated $\mathrm{CCN}$ concentrations showed a log-linear decrease with increasing altitude, similar to the observed profile.

Second, the horizontal distribution of the liquid cloud properties in the nested model simulations was compared with that estimated from data of the Modulate Resolution Imaging Spectroradiometer on the Terra satellite (Terra/MODIS) based on the satellite's retrieval algorithm (Nakajima and Nakajima 1995; Nakajima et al. 2005); plots of the horizontal distribution are shown in Fig. 6 of IG08. Figure 3 shows the relationship between the liquid cloud-top temperature and the droplets' effective radius near the cloud tops in the satellite measurements and the simulation for the April 2 case. These parameters were averaged separately in the northern and southern halves of the simulation domain to highlight spatial differences in the droplet radius distribution. The north-south difference is likely to have resulted from a horizontal bias in the $\mathrm{CN}$ concentration. The model simulation performed satisfactorily in reproducing the overall tendency of the north-south gradients of the observed droplet radius in warm-cloud regimes with temperatures in excess of $273 \mathrm{~K}$, despite some overestimation (Fig. 3a). The observed radius monotonously increased with decreasing cloud-top temperature. The observed radii averaged in the northern half had larger values than those in the southern half; the maximum north-south difference was roughly $5 \mu \mathrm{m}$. The simulated radius generally increased with decreasing cloudtop temperature down to $275 \mathrm{~K}$ and roughly decreased or remained constant below $275 \mathrm{~K}$. The simulated radii in the northern half attained larger values than those in the southern half for temperatures greater than $275 \mathrm{~K}$; the north-south difference was roughly $5 \mu \mathrm{m}$ on average. In addition, two sensitivity simulations were conducted to highlight the effects of the aerosol loading module on the simulation results (Fig. 3b, c). The simulation assuming horizontally homogeneous initial and boundary $\mathrm{CN}$ conditions failed to reproduce the structure of the north-south gradients (Fig. 3b). The simulated profiles of the average droplet effective radius are almost identical for the northern and southern halves. The simulated north-south gradients in the control run were thus caused by a horizontally inhomogeneous $\mathrm{CN}$ distribution introduced by aerosol downscaling. This result proved that the implementation of realistic, inhomogeneous $\mathrm{CN}$ fields is essential for more accurate simulations of cloud microphysical properties. On the other hand, the simulation assuming a doubled $\mathrm{CN}$ number concentration compared with the control run had smaller effective radii (Fig. 3c). The simulated effective radius profiles were in better agreement with the observed profiles than those in the control run. This result indicates that the control run underestimated the $\mathrm{CCN}$ number concentration.

\section{Update by Choi et al. (2014): Aerosol particle size distribution revision and type multiplication}

The IG08 version of ALICIS still contained many limitations. Among them was the absence of two aerosol species, i.e., black carbonaceous aerosol and dust particles. In reality, they often work as $\mathrm{CCN}$ if soluble components are combined with the particles, either externally or internally (e.g., Sullivan et al. 2009). In addition, the modeling of the other three types of aerosol still offered room for significant improvements. For example, the application of a power-law function to the size distribution spectra of sea salt aerosol might cause an overestimation of the activated $\mathrm{CCN}$ number concentration because of the continuous increase in the $\mathrm{CCN}$ number concentration with increasing supersaturation.

The aerosol loading module was comprehensively updated by $\mathrm{CH} 14$. The conversion from the various types of aerosol to standardized CN, as implemented by IG08, has been removed. The same five aerosol species used in the SPRINTARS model are employed in nested models. The discretization of the size distribution spectra of each aerosol type has been extended to 17 size bins with radii ranging from $10^{-3}$ to $10 \mu \mathrm{m}$. The use of more size bins and a wider range of particle sizes compared with those in the old version allows the representation of aerosol particles with radii larger than $1 \mu \mathrm{m}$. Such large aerosol particles are possibly included in the sea salt and dust aerosol categories (Fig. 4).

The size distribution function of each aerosol type was assumed to be of a multi-modal lognormal form by $\mathrm{CH} 14$. The size distribution spectra described in this manner are consistent with those observed in reality (e.g., Brechtel et al. 1998). The number density concentration of the size distribution of each aerosol type is given by 
(a) April 2, 2003

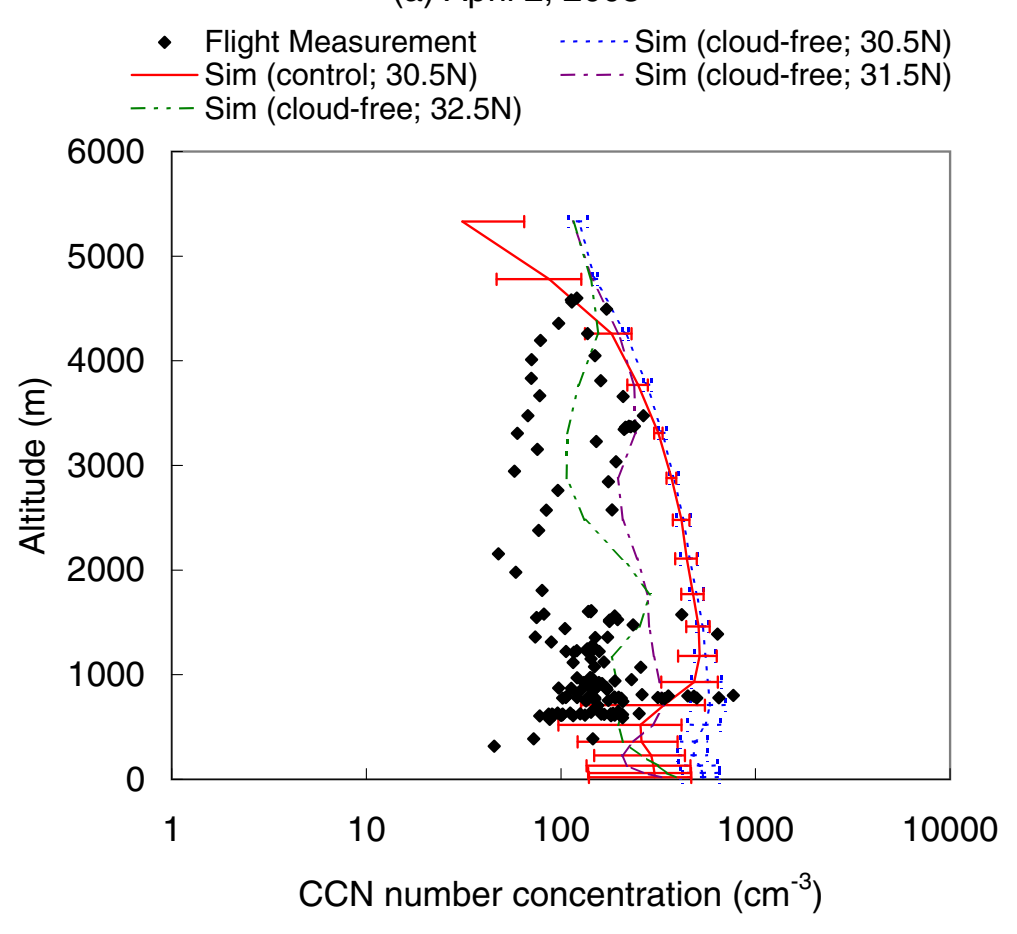

(b) April 8, 2003

- Flight Measurement

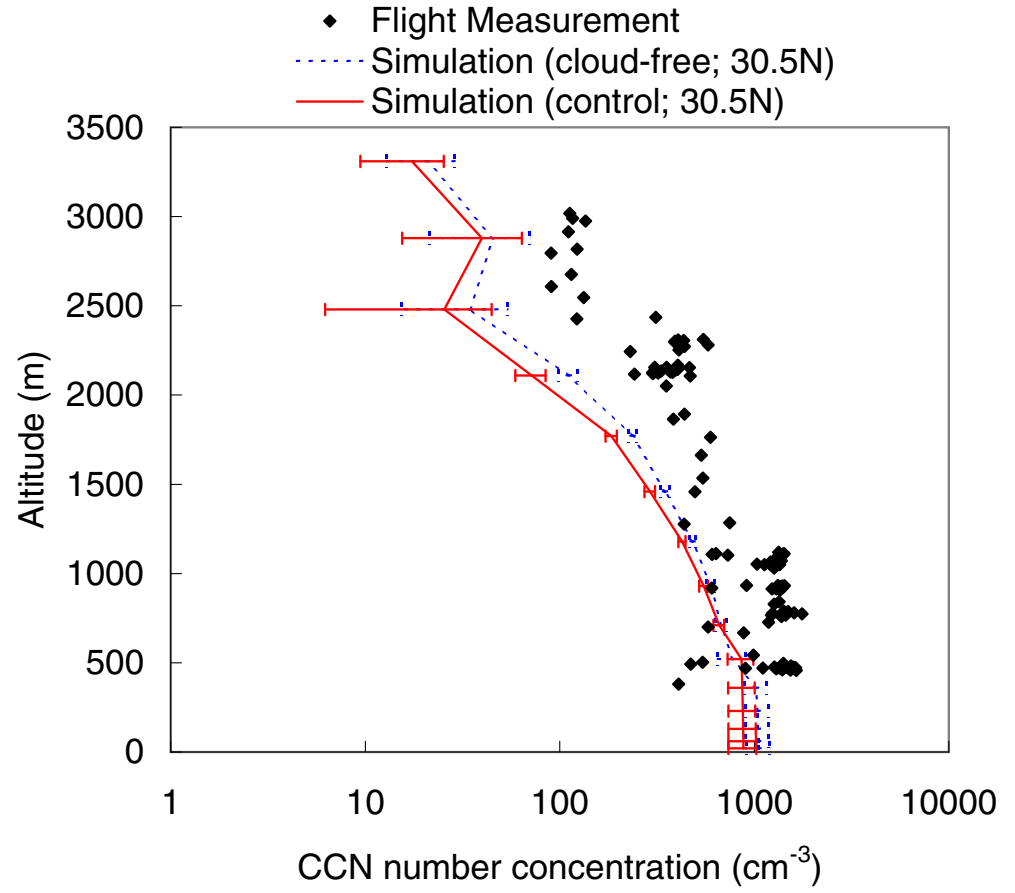

Fig. 2 Vertical distribution of the observed and simulated CCN number concentrations over the East China Sea on a April 2, 2003 and b April 8, 2003. The observed CCN number concentration in the flight measurements was obtained for liquid-phase supersaturation ranges of $0.07-0.22 \%$ on April 2 and $0.09-0.32 \%$ on April 8 . The simulated CCN number concentration in the regional model was calculated for a liquid-phase supersaturation of $0.1 \%$ in the April 2 case and $0.2 \%$ in the April 8 case. Lines of simulated concentration show vertical profiles of horizontal averages in three domains of radius $\pm 0.5^{\circ}$ centered at $129.5^{\circ} \mathrm{E}$ and $30.5^{\circ} \mathrm{N}, 31.5^{\circ} \mathrm{N}$, or $32.5^{\circ} \mathrm{N}$. The two types of simulated concentration are plotted separately from the control and cloud-free runs (where all cloud microphysical processes were switched off to prevent CN consumption through droplet nucleation). Adapted from lguchi et al. (2008) 


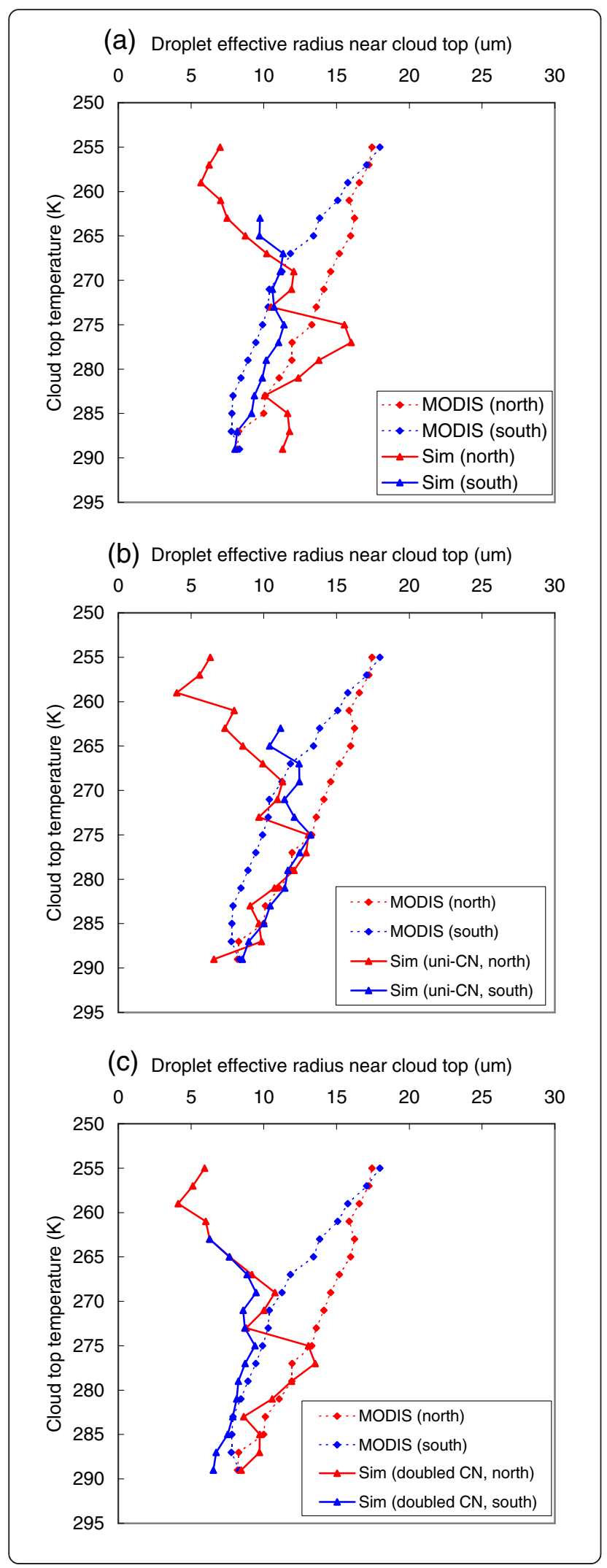

Fig. 3 Dependence of droplet effective radii near cloud tops on cloud-top temperature calculated based on simulations with three different settings and from the retrieval results derived from Terra/ MODIS measurements over the East China Sea on April 2, 2003. Simulation profiles are calculated in $\mathbf{a}$ the control run, $\mathbf{b}$ the run characterized by a homogenous $\mathrm{CN}$ field, and $\mathbf{c}$ the run with doubled CN. Plotted radii are averaged individually in the northern and southern halves of the analysis domain. Adapted from lguchi et al. (2008)

$$
\frac{\mathrm{d} N}{\mathrm{~d}\left(\ln r_{a}\right)}=\sum_{i=1}^{n_{\mathrm{m}}} \frac{N_{\mathrm{SPR}} f_{i}}{\sqrt{2 \pi} \sigma_{i}} \exp \left(-\frac{\ln r_{a}-\ln r_{m i}}{2 \sigma_{i}^{2}}\right)
$$

where $r_{\mathrm{a}}$ is the aerosol particle radius, $i$ the index of a given mode, $n_{\mathrm{m}}$ the total number of modes in the size distribution, $N_{\text {SPR }}$ the bulk number concentration of each aerosol type obtained from the SPRINTARS simulation, and $f$ the weight factor required to normalize the multi-modal distribution. The variables $n_{\mathrm{m}}, f, r_{\mathrm{m}}$, and $\sigma$ are the functions of aerosol type as listed in Table 1 of $\mathrm{CH} 14$; the values have been determined on the basis of observational results (d'Almeida et al. 1991; Chuang et al. 1997; Penner et al. 1998; Herzog et al. 2004).

Figure 4 compares the aerosol size distribution spectra. Two size distribution spectra were calculated for each aerosol type using the assumptions employed by CH14 and IG08. No size distribution was assumed for dust or black carbonaceous aerosol in the study by IG08. A set of observed spectra was obtained from in situ measurements during the ACE-Asia field campaign in 2001 (Huebert et al. 2003). The set of spectra was calculated from the size-segmented aerosol mass concentration measured using the Micro-Orifice Uniform Deposit Impactor (MOUDI) onboard a research vessel; the marine aerosol sampling performed during ACE-Asia 2001 is summarized by Mochida et al. (2007). Another set of observed spectra was obtained from ground-based measurements using MOUDI at the Gosan site on Jeju Island (Republic of Korea) during the Atmospheric Brown Cloud-East Asian Regional Experiment (ABC-EAREX) in 2005 (Nakajima et al. 2007).

In Fig. 4, the size distribution spectra employed by $\mathrm{CH} 14$ are in better agreement with those from the measurements, although the observed size spectra lack multi-modal distributions. The observed aerosol number densities monotonously decrease with increasing aerosol particle size. The observed size distributions of sulfate and organic/black carbonaceous aerosol extend to the radii of $2 \mu \mathrm{m}$, whereas those of dust and sea salt aerosol extend to over $5 \mu \mathrm{m}$. The spectra of $\mathrm{CH} 14$ reproduce the distinct structure of the observed spectra according to aerosol type reasonably well, especially 


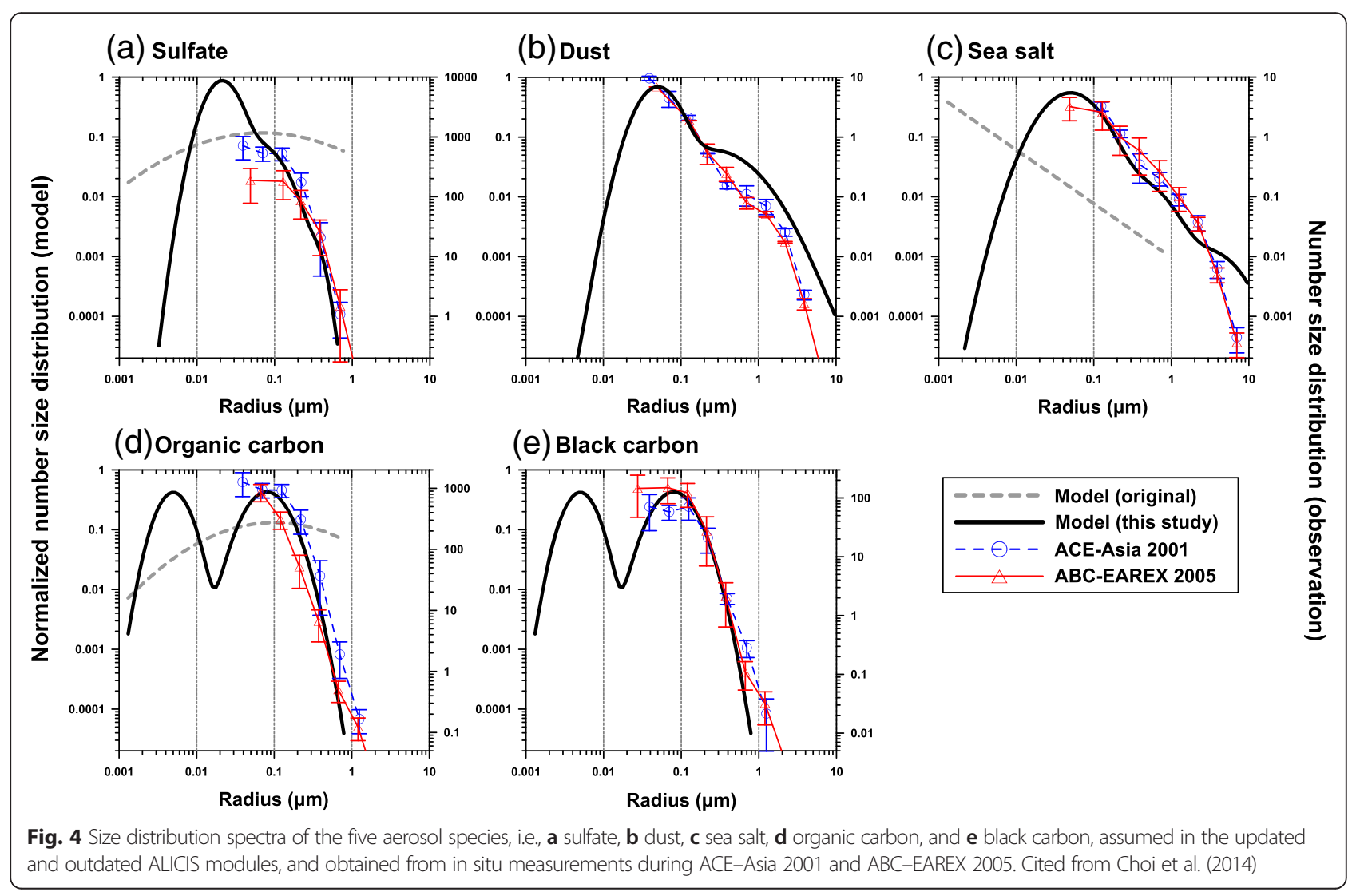

those of sulfate and organic/black carbonaceous aerosol. In contrast, the spectra of IG08 exhibit several severe insufficiencies. The number density concentration of sulfate aerosol is overestimated across the full particle size range shown and the sea salt aerosol concentration is significantly underestimated. The organic carbonaceous aerosol concentration is underestimated for particle radii smaller than $0.1 \mu \mathrm{m}$ and overestimated for radii larger than $0.4 \mu \mathrm{m}$.

The activation process of aerosol particles to form cloud droplets was calculated for each aerosol type on the basis of basic Köhler theory by CH14, unlike in IG08. Because the five types of aerosol have different soluble capabilities, different $B$ coefficients are employed in determining the critical radius of $\mathrm{CCN}$ in Eq. 11 . The $B$ coefficients are assumed to be 0.51 for sulfate, 1.16 for sea salt, 0.14 for dust, 0.14 for organic carbonaceous, and $0.05 \times 10^{-5}$ for black carbonaceous aerosol (Ghan et al. 2001).

$\mathrm{CH} 14$ employed the same build-up process of initial and time-variant boundary conditions of binned aerosol concentrations in their nested model simulations as IG08. The time evolution of each binned concentration was numerically computed for each time step. Microphysical processes producing or losing aerosol particles were excluded, except for consumption through the nucleation of cloud droplets.
Any direct aerosol effects on atmospheric radiation were excluded, even by $\mathrm{CH} 14$, although the five types of aerosol were fully managed.

$\mathrm{CH} 14$ evaluated the performance of the updated version of the aerosol loading module in their simulation analysis. They conducted numerical simulations of two cloudy cases observed during the ABC-EAREX 2005 field campaign over an East China Sea region. Corresponding simulations using the old version of the aerosol loading module of IG08 were performed simultaneously for comparison.

First, the simulated $\mathrm{CN}$ and $\mathrm{CCN}$ number concentrations were evaluated in comparison with those obtained from ground-based measurements. The $\mathrm{CN}$ comparison yielded a new perspective on the validation of ALICIS, in addition to the $\mathrm{CCN}$ comparison also discussed by IG08. Figure 5 compares the concentrations (CCN at $0.6 \%$ supersaturation) derived from the different assumptions made by both IG08 and $\mathrm{CH} 14$ with those obtained from in situ measurements at the Gosan site. The observed $\mathrm{CN}$ and $\mathrm{CCN}$ concentrations were measured using a TSI (Shoreview, MN, USA) condensation particle counter model 3010, which detected particles with diameters larger than $10 \mathrm{~nm}$, and using a streamwise thermal-gradient $\mathrm{CCN}$ counter (Roberts and Nenes 2005); details of the measurements can be found in Yum et al. (2007). The large underestimation of the 
(a)

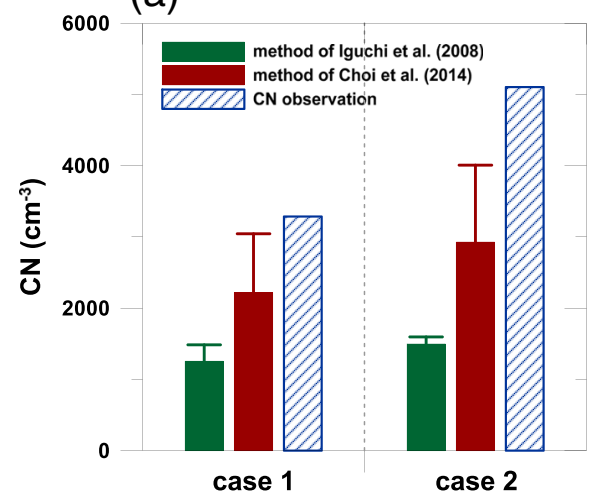

(b)

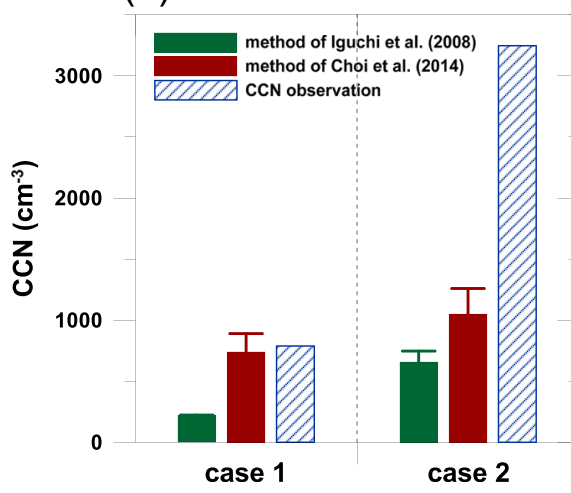

Fig. 5 Surface-level a CN and b CCN (at $0.6 \%$ liquid-phase supersaturation) number concentrations simulated near the ABC-EAREX 2005 Gosan site and measured at the site on March 13, 2005 (case 1) and March 25, 2005 (case 2). Green bars show number concentrations in a regional model simulation using the ALICIS module based on Iguchi et al. (2008); the concentrations are calculated at grid points near the site (averaged within an area of $126.0^{\circ} \mathrm{E}-126.4^{\circ} \mathrm{E}$ and $33.1^{\circ} \mathrm{N}-33.5^{\circ} \mathrm{N}$ at the model bottom level) for the initial time step of the simulation. Error bars show standard deviations from the averages. Red bars show the same concentrations but using assumptions proposed by Choi et al. (2014). Observed CN and CCN were measured simultaneously using a TSI condensation particle counter and a stream-wise thermal gradient CCN counter deployed at the Gosan site, respectively

number concentrations in the outdated IG08 version has been alleviated in the updated $\mathrm{CH} 14$ version. The improvement is attributed to the application of more realistic distribution functions to the aerosol size spectra rather than the new inclusion of dust and black carbonaceous aerosol into the categories. However, underestimation of $\mathrm{CN}$ and $\mathrm{CCN}$ concentrations still remained in the simulations using the updated $\mathrm{CH} 14$ version, especially for the second case. This insufficiency is probably caused by an underestimation of the aerosol concentration in the SPRINTARS simulation over highly polluted regions affected by anthropogenic aerosol emissions.

Second, $\mathrm{CH} 14$ evaluated droplet effective radii near cloud tops, liquid water paths, and cloud optical thicknesses calculated in their simulations in comparison with those obtained from the Terra/MODIS satellite measurements through retrieval (see Table 2 in CH14); details of the retrieval algorithm are described by Nakajima et al. (2005). Simulations using the updated and outdated aerosol loading modules led to different values of the variables, although the cloud distribution patterns were similar. The droplet effective radii were smaller, and the liquid water paths and cloud optical thicknesses were larger in the updated simulation compared with the outdated simulation. These differences resulted from larger CDNC attributed to the larger $\mathrm{CN}$ and $\mathrm{CCN}$ number concentrations. Overall, the values in the updated simulation were in better agreement with those estimated from the satellite measurements, reflecting the better reproduction of the $\mathrm{CN}$ and $\mathrm{CCN}$ concentrations in the updated version.
Update by Sato et al. (2012): Aerosol emission from evaporated cloud droplets

SA12 introduced an aerosol particle generation process from completely evaporated droplets into the framework of the HUCM SBM, coupled with the ALICIS module. Absence of an aerosol regeneration process might cause underestimation of the $\mathrm{CN}$ and $\mathrm{CCN}$ number concentrations and, consequently, an underestimation of CDNC, particularly in long-term simulations. The process was not included in the original HUCM SBM, and was not considered by IG08 or CH14, mostly because of the following technical issue. Once the activation to droplet nucleation has been calculated in the models, the size and composition information about the aerosol particles used was eliminated. Some state-of-the-art models fully predict solute components in hydrometeor particles at the expense of increased computational cost (e.g., Chen and Lamb 1994). Such models have the advantage of enabling explicit calculations of aerosol particle emission from completely evaporated or sublimated hydrometeor particles.

The parametrization of the aerosol emission process by SA12 was based on the third approach described by Feingold et al. (1996). SA12 assumed that one aerosol particle was regenerated when one droplet had completely evaporated (Mitra et al. 1992). Solute components in the droplet were not fully predicted, so that the sizes of regenerated aerosol particles could not be calculated explicitly; alternatively, the size distribution spectrum of the regenerated aerosol was determined based on the change of the domain-averaged aerosol number concentration from the initial condition to the present time step. The additional aerosol number 
concentration to the $k$-th aerosol size bin resulting from this regeneration process $\left(R_{\mathrm{k}}\right)$ is as follows (see Eqs. 3 and 4 in Feingold et al. 1996):

$$
\begin{aligned}
& R_{\mathrm{k}}=N_{\mathrm{R}} \frac{\phi_{k}}{\sum_{k=1}^{n_{\text {bin }}} \phi_{k}} ; \\
& \phi_{k}=\frac{\bar{N}_{0, \mathrm{k}}-\bar{N}_{\mathrm{k}}}{\bar{N}_{0, \mathrm{k}}},
\end{aligned}
$$

where $N_{\mathrm{R}}$ is the total number concentration of the regenerated aerosol particles, which is equivalent to the number concentration of completely evaporated droplets; $n_{\mathrm{bin}}$ is the total number of aerosol size bins; and $\bar{N}_{0, \mathrm{k}}$ and $\bar{N}_{\mathrm{k}}$ are the domain-averaged aerosol number concentrations of the $k$-th size bin in the initial and present conditions, respectively. SA12 assumed that all $\mathrm{CN}$ were composed of ammonium sulfate; therefore, the chemical component of aerosol particles generated through this emission process was assumed to be ammonium sulfate.

SA12 evaluated the performance of the aerosol regeneration parametrization in their simulations by resolving stratocumulus over a region off the coast of California. Two types of simulation (i.e., with and without the regeneration parametrization) were conducted simultaneously to investigate the influence of this process. The simulation results were validated using retrieval results from the space-borne AVHRR/2 data over the region of interest (Nakajima and Nakajima 1995).

Figure 6 shows the horizontal distribution of the cloud optical thickness retrieved from the AVHRR/2 spaceborne measurements (Nakajima and Nakajima 1995) and calculated in the regional model simulations excluding or including the aerosol regeneration process. Cloud optical thickness ranged from 10 to 60 over the domain of interest in the observation region. The southern half of the domain exhibited relatively thick stratocumulus. In contrast, the simulated cloud fields show a more dispersed structure. Cloud optical thicknesses simulated with the aerosol regeneration parametrization were at least in better agreement with the satellite measurements than those not based on this parameterization. Large optical thicknesses of more than 30 are patchily and widely distributed in the simulation including the regeneration process, whereas the corresponding values were less than 20 in the simulation without the regeneration process, except for areas that were close to a lateral boundary of the simulation. Implementation of the aerosol regeneration process caused an increase of approximately $20 \%$ in the aerosol number concentration averaged over the domain. A large fraction of aerosol particles emitted from evaporated droplets was used again as CCN. The regeneration of aerosol particles caused increased CDNC and cloud optical thickness.

Sato (2012) tested another approach used by Feingold et al. (1996) for the aerosol regeneration process, because the parametrization based on Eq. 5 was not very appropriate for downscaled realistic simulations. The new approach assumed that the particle size distribution of regenerated aerosol was the same as the horizontal average at the corresponding vertical level for the initial conditions. Sato's (2012) tests using this approach showed that the reproducibility of cloud optical thickness was improved as well.

SA12 also conducted a quantitative comparison on the basis of correlation analysis between the droplet effective radii and cloud optical thicknesses (e.g., Fig. 8 of SA12). Only simulations including the aerosol regeneration parametrization reproduced a characteristic pattern in the correlation plots based on the satellite measurements. Their results demonstrate that implementation of the aerosol regeneration process is necessary to adequately simulate the cloud microphysical structure of stratocumulus over the region of interest.

\section{Prospective ALICIS update strategy \\ IN modeling}

The behavior of aerosol particles as IN is implicitly included in the framework of the HUCM SBM tied to the present ALICIS module. The IN effect is tacitly contained in parametrizations to calculate ice-nucleation and freezing processes without consumption of predicted aerosol particles in the model. This coarse approach is due to the present poor knowledge about complicated microphysics in ice/mixed-phase clouds. Nevertheless, introducing an explicit representation of IN activation and the resultant depletion is important for developing a more comprehensive scheme of cloud microphysics for aerosol-cloud interaction studies. Improvement of the SBM and ALICIS to manage the IN effect is a worthwhile challenge.

Solid hydrometeor particles in the atmosphere primarily form through either homogenous freezing of supercooled droplets without IN action or heterogeneous nucleation/freezing with catalysis by IN. In addition, the latter heterogeneous processes can be divided into four different categories (Vali 1985): deposition nucleation, condensation-freezing nucleation, contact freezing, and immersion freezing.

Deposition nucleation is completed when water vapor directly deposits onto the surface of an aerosol particle, provided that supersaturation with respect to ice is positive. The aerosol particle does not have to be hydroscopic. On the other hand, condensation-freezing nucleation originates from the nucleation process of a droplet under the condition that supersaturation with respect to water is positive. The aerosol particle is activated as $\mathrm{CCN}$ but does not have 
(a) AVHRR/2-derived cloud optical thickness at 1500 UTC July 10, 1987

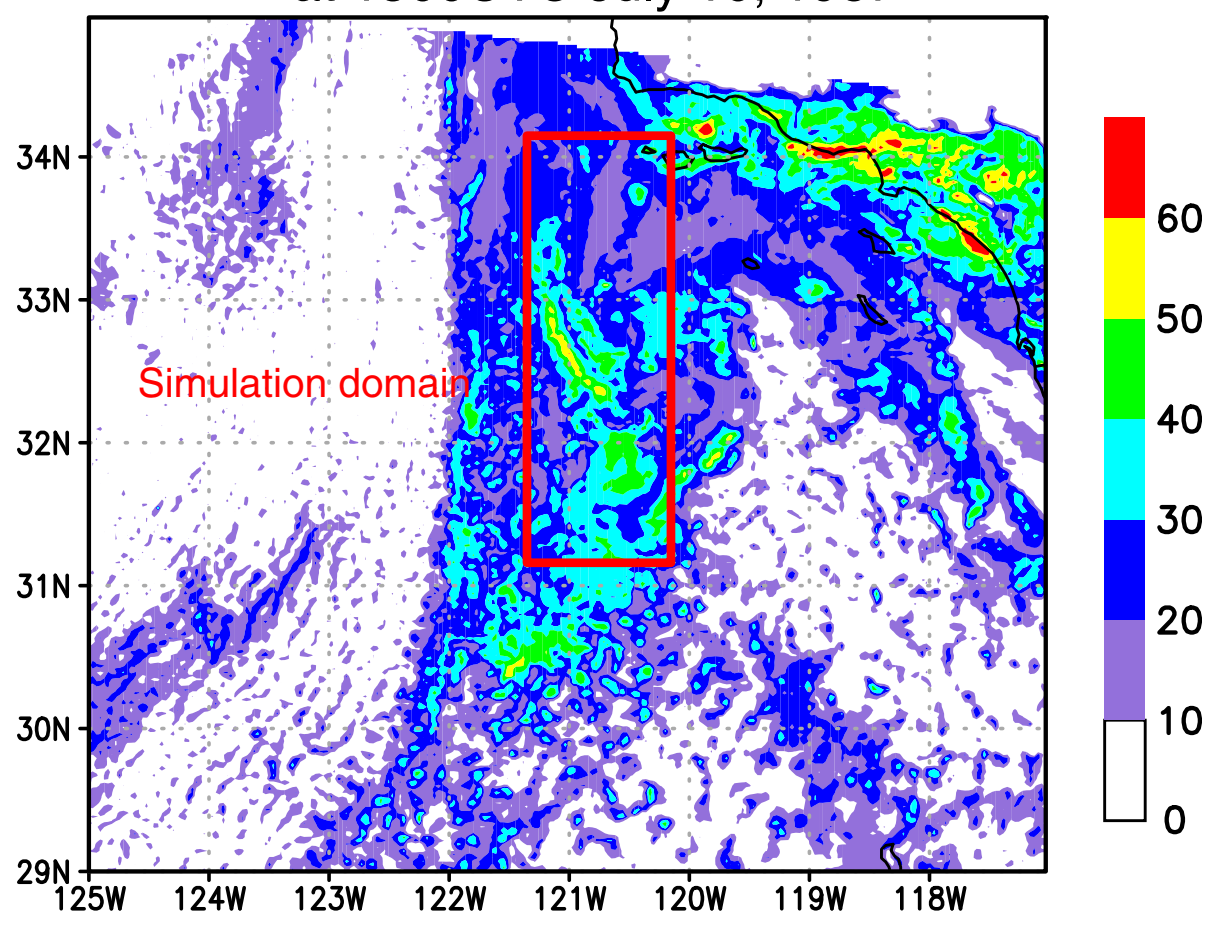

(b) CTL-run

(c) RGN-run
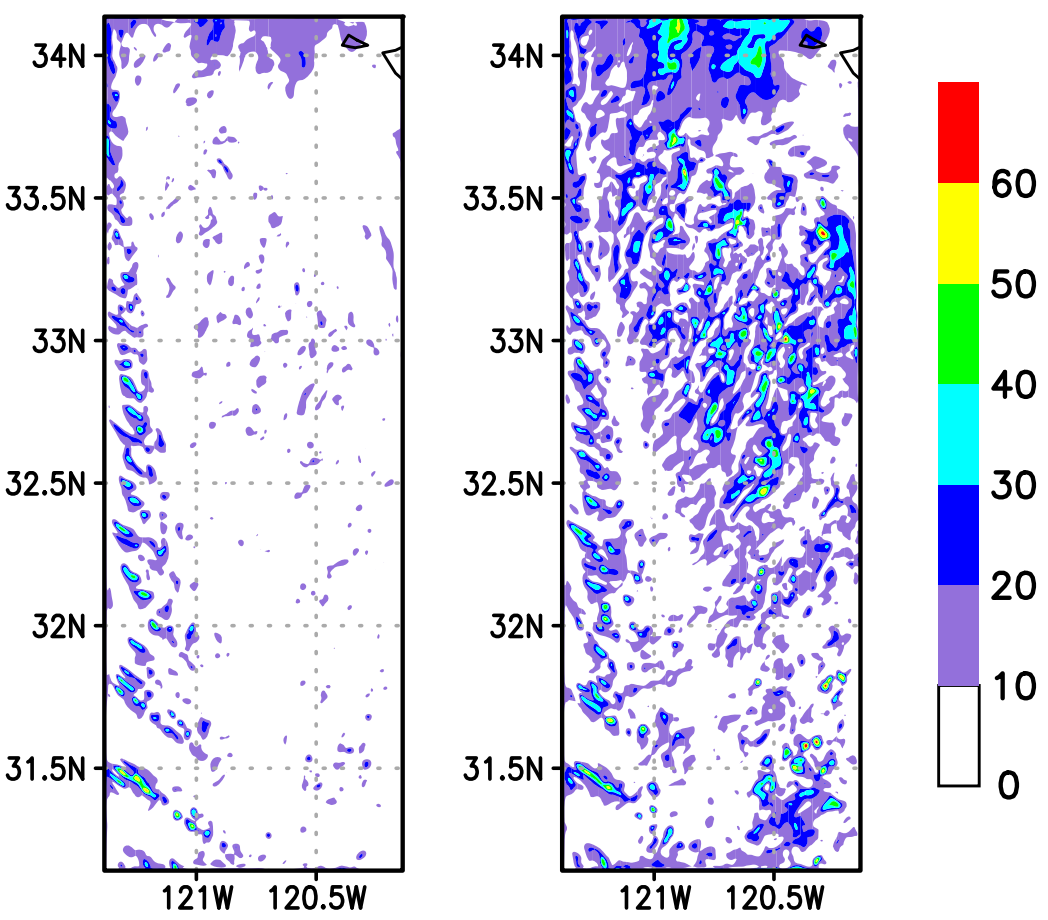

Fig. 6 Horizontal distribution of cloud optical thickness observed at 1500 UTC on July 10, 1987: a retrieved from the space-borne AVHRR/ 2 measurement results, $\mathbf{b}$ simulated by the regional model without aerosol regeneration parametrization (CTL-run) at 1400 UTC on the same day, and $\mathbf{c}$ with regeneration parameterization (RGN-run). The red rectangle in the top panel shows the model simulation domain 
to completely dissolve in the droplet. The droplet that is formed then immediately freezes from the non-dissolved impurity. Distinguishing these two types of nucleation process is difficult in measurements where supersaturation with respect to water is positive. Supersaturation (i.e., humidity) rather than temperature is an important factor controlling the progress of these processes. Contact freezing possibly occurs when supercooled droplets collide with aerosol particles. The collision is usually caused by Brownian diffusion, thermophoresis, diffusiophoresis, electrophoresis, and/or inertial impaction. The concentration of aerosol particles that can act as contact-freezing IN at the relevant temperature is the most important factor in determining the freezing probability. Immersion freezing originates from impurities already present inside a supercooled droplet. Unlike condensation-freezing nucleation, immersion freezing does not have to start immediately upon the formation of a supercooled droplet. The freezing can occur when the temperature of the supercooled droplet decreases.

Among the four types of heterogeneous cloud glaciation processes, deposition nucleation is the simplest because the process does not proceed through a state of supercooled droplets. An increase in the number of aerosol particles that can work as deposition IN directly causes the number of ice cloud particles to increase, just like the relationship between $\mathrm{CCN}$ and cloud droplets. In contrast, cloud glaciation through the other three processes is more complicated. If the number concentrations of all types of aerosol increase, promotion of heterogeneous freezing through increasing IN may be in competition with depression of the freezing efficiency caused by a decrease in the particle sizes of supercooled droplets through increasing CDNC. In contrast, increased cloud height and decreased cloud temperature caused by the particle size change of supercooled droplets (e.g., Pincus and Baker 1994) may accelerate cloud glaciation through heterogeneous or homogenous freezing.

Unlike droplet nucleation summarized in Köhler theory, no comprehensive theory has been developed to formulate each ice-nucleation or freezing process. Parametrizations of these processes are constructed empirically on the basis of in situ measurement data or experimental laboratory data acquired under certain conditions. The four types of mechanisms of heterogeneous nucleation/freezing can rarely be distinguished through measurements or experiments, so that empirical parametrization may cover multiple components for each of the four types of the mechanisms. In addition, identifying the chemical components of IN is difficult for most measurements.

Appendix 2 summarizes our testbed for how to improve IN parametrization in the HUCM SBM coupled with the ALICIS module. Fan et al. (2014) improved the ice-nucleation parts of the HUCM SBM by introducing up-to-date IN parametrizations that include prognostic dust aerosol concentrations. The parametrizations were based on results by Tobo et al. (2013) and DeMott et al. (2015) for deposition/condensation-freezing nucleation and immersion freezing, and by Muhlbauer and Lohmann (2009) for contact freezing. We may modify the parametrizations into suitable forms to use the aerosol size distribution spectra predicted by models coupled with the ALICIS module. In addition, more comprehensive and generalized parametrizations of heterogeneous ice-nucleation/freezing should be implemented in future updates. Phillips et al. $(2008,2013)$ proposed a flexible framework where various empirical parametrizations can be bundled into a versatile form since parameters in the formulation can be easily constrained by various observational data. Note that the application of any proposed parametrizations to actual model simulations is still affected by large uncertainties. The uncertainties come from the limited applicability of findings from in situ measurement and laboratory experiment results for IN, and the coarse translation from results to developerfriendly parametrizations in a numerical scheme.

\section{Introduction of regional variability into the aerosol size distribution and hygroscopicity parameters}

The present ALICIS module includes fixed aerosol size distribution functions with constant parameters, as described in "An early version of ALICIS: Iguchi et al. (2008)". The size distribution spectra were validated for application to simulations of regions in Northeast Asia through comparisons with those obtained from on-site measurements. The spectra might thus be inappropriate if applied to simulations pertaining to other regions. For example, mineral dust aerosol particles in East Asia and North Africa (Sahara) have different physical and chemical properties (Formenti et al. 2011). The dust properties depend not only on the source region but also on the distance from the emission site.

We will introduce regional variability into the aerosol size distribution functions and the hygroscopicity parameters assumed in the ALICIS module. First, these functions and parameters should have different forms and values in accordance with the type of simulation region, e.g., continental, coastal, or maritime. For example, the parameters determining the particle size distribution of sulfate aerosol used by $\mathrm{CH} 14$ originate from those for maritime scenes from Chuang et al. (1997). The latter authors assumed a bimodal function with different parameter values for continental regions instead of the trimodal function employed for maritime scenes. An average of the two size spectrum forms can also be used for intermediate (i.e., coastal) scenes. 
Second, introducing intercontinental variability into the ALICIS module is a valuable challenge for further improvement. Although many measurements of the aerosol size distribution have been conducted worldwide, most obtained a bulk aerosol size distribution containing all chemical components. Internal mixing of aerosol particles is highly problematic in constraining the aerosol size distribution of an individual chemical component in relation to the measurement data. Few recent studies have conducted global simulations using an aerosol transport model predicting the aerosol size distribution (e.g., Spracklen et al. 2005; Zhang et al. 2010; Jacobson 2012). These simulation results are useful for complementary provision of aerosol size distribution information, particularly over pelagic regions and in the upper troposphere where few in situ measurements are available. The results may be employed to construct climatology data of the aerosol size distribution or they may be used as direct input to simulations through dynamical downscaling approaches.

\section{Introduction of aerosol representation to internal mixing, source/sink, and direct radiative effects}

Compared with typical aerosol transport models, the present SBM coupled with the ALICIS module still lacks modeling of many aspects of aerosol behavior and its effects. Some may have a critical influence on cloud microand macrophysics. Their implementation is necessary to conduct more comprehensive simulations of aerosol-cloud interactions (e.g., Saleeby and van den Heever 2013). Various approaches have been proposed to introduce these aspects into models. We will include them in future updates while considering the limitations of the available computational resources.

In reality, aerosol particles are often characterized by internally mixed states with multiple chemical compositions. These aerosol particles are mostly dominant in regions at great distances from their major emission sources. The chemical and physical properties of aerosol particles may change through gas absorption/deposition or they may coagulate with other particles during migration. The question of how to numerically model an internal mixture is a delicate problem in calculating the nucleation process of cloud hydrometeor particles from aerosol particles, as well as their scattering and absorption of atmospheric radiation. Various modifications of the Köhler theory have been proposed to represent the hygroscopic growth of internally mixed particles. For example, reformulation of the Köhler equation was suggested to consider the effects of soluble gases and slightly soluble solid substances in the droplet nucleation process (Laaksonen et al. 1998). A modified Köhler theory with a single solute hygroscopicity parameter ( $k$-Köhler theory) has also been proposed (Petters and Kreidenweis 2007); the new parameter represents the $\mathrm{CCN}$ capability of dry particles with arbitrary mixtures and can be constrained easily with observational data.

Wet scavenging (i.e., impaction of aerosol particles by hydrometeor particles) does not only cause a significant decrease in aerosol concentration but also triggers several cloud microphysical processes, such as contact or immersion freezing. The scavenging process is divided into two types: dissolution or impaction as a result of the nucleation process through condensation or deposition of water vapor on aerosol particles, and impaction through collision between aerosol particles and already extant hydrometeor particles. As highlighted in the section about contact freezing, Brownian diffusion, thermophoresis, diffusiophoresis, electrophoresis, and/or inertial impaction are major causes of collisions between aerosol and hydrometeor particles. There are significant uncertainties associated with modeling these effects, especially as regards the electromagnetic attraction between aerosol and hydrometeor particles, because of insufficient theoretical knowledge and measurement data. In addition, tracing solutions and impurity components in hydrometeor particles is technically difficult if only limited computational resources are available. At present, a few models explicitly predict solution and impurity components in hydrometeor particles in their SBM frameworks (e.g., Chen and Lamb 1994). As an alternative approach, solution and impurity components are assumed to be statistically (Poissonian) distributed according to the volume of a hydrometeor particle when the total mass of the components scavenged by hydrometeor particles is predicted (Phillips et al. 2008). Although these authors applied this approach to their parametrization for immersion freezing, the same approach is applicable to the calculation of aerosol particle emission from evaporated hydrometeor particles.

Scattering and absorption of atmospheric radiation by aerosol particles can change the radiation budget in the different atmospheric layers and on the Earth's surface; this is a well-known direct effect of aerosol on the Earth's radiation balance. Direct aerosol effects on atmospheric radiation have a little impact on cloud physics. However, strong absorption of the solar irradiance by aerosol particles potentially has a drastic influence on cloud structure. Heating through absorption may affect the surroundings of the particles on a minor scale. When such absorptive aerosol particles or impurities in hydrometeor particles exist in great volumes at layers near the cloud top, an increase in temperature through heating may promote evaporation of hydrometeor particles. This effect may cause a change in the Earth's radiation balance through cloud structure change. This kind 
of aerosol influence is referred to as the aerosol semidirect radiative effect (Ackerman et al. 2000).

Aerosol optical properties are a key determinant of their influence on the Earth's radiation budget. We plan to follow standard methods employed in existing aerosol transport models (e.g., GOCART, SPRINTARS, ECHAM: Pozzoli et al. 2011; the Hadley Centre Global Environment Model HadGEM: Bellouin et al. 2011) to determine the aerosol optical properties. The single-scattering properties of spherical aerosol particles can be approximated using Mie scattering theory in radiative flux calculations. The wavelength of light, the radius of a particle, and the refractive index of its medium at the relevant wavelength are required to determine the extinction coefficient, single-scattering albedo, and asymmetry factor. The effect of water uptake on hygroscopic aerosol particles is approximated by calculating the particle radius and refractive index for a series of relative humidity values; the refractive indices are calculated on the basis of the volume-weighted mixing assumption between water and dry components (e.g., Haywood et al. 1997; Takemura et al. 2002; Eq. 3). The internal mixture effect is also approximated using the volume-weighted mixing assumption for multiple different components. Non-spherical dust particles are approximated as their corresponding spherical particles in calculating their optical properties, because relative errors introduced by this assumption are very small ( $\mathrm{Fu}$ et al. 2009). We will generate lookup tables of extinction coefficients, single-scattering albedos, and asymmetry factors computed using a Mie theory program for the discretized series of aerosol particle radii, relative humidity values, and band wavelengths as applicable to each aerosol type. An internal mixture will be assumed only for organic and black carbonaceous aerosol particles at this stage to avoid heavy computational loads by including all mixture combinations; lookup tables for the mixed particles will also be prepared.

\section{Conclusions}

This review paper describes the scientific background and update strategies in the development of the aerosol loading module referred to as ALICIS. The module is used for coupling a downscaled CRM simulation with a large-scale aerosol transport simulation. The most important function of the module is to provide realistic temporally and spatially inhomogeneous distributions of aerosol combined with accurate aerosol size distribution information for downscaled simulations. Introduction of the module yields better simulations of cloud microphysical structure by avoiding the adoption of inadequate aerosol loading as artificially defined by users.

ALICIS has been subject to two major updates since its initiation by IG08. The assumption of the aerosol size distribution spectra was significantly improved as the spectrum shapes better matched their observed counterparts in the first update (CH14). The aerosol emission process from evaporated cloud droplets was added in the second update (SA12). However, many points remain to be improved in future updates, including but not limited to the management of heterogeneous ice nucleation/freezing, aerosol direct/semi-direct effects on atmospheric radiation, addressing internal mixtures of different chemical components in aerosol particles, the introduction of regional variability into the aerosol size distribution, and the representation of wet scavenging.

So far, ALICIS has been employed only in the framework connecting SPRINTARS aerosol transport simulations to JMA-NHM coupled with the HUCM SBM. We are now working on implementing the aerosol loading module into the bridge between the Modern Era Retrospective analysis for Research and Applications Aerosol Reanalysis (MERRAero) or GEOS-GOCART model simulations and WRF coupled with HUCM SBM (WRF-SBM) (e.g., Iguchi et al. 2012a). This extension will readily increase the applicability of ALICIS to more diverse simulation scenes and styles. In addition, we plan to develop the coupling of ALICIS to bulk cloud microphysics instead of SBM to enhance the simulation capability.

In future updates, models coupled with the ALICIS module will include a more comprehensive representation of aerosol and related chemical species, like the WRF-Chem model. Such state-of-the-art models also enable better simulation of cloud microphysics, although they require much larger computational resources and loads. Improvement in model functionality is in competition with improvement in various resolutions such as spatial grid spacing, time-step sampling, and/or particle size bins. Keeping a balance between model performance and computational efficiency in the context of limited resources is a delicate problem in model development. Adequate sorting of the priorities between the introduction of various model functions and improvement in various resolutions is an important task assigned to researchers.

\section{Appendix 1: Basic Köhler theory for droplet nucleation}

A chart of Köhler curves (Köhler 1936) summarizes a fundamental theory about $\mathrm{CN}$ activation and stabilization of the formed droplets. The chart illustrates relationships between the ambient vapor saturation ratio and droplet radius under equilibrium conditions with the environment. Two competitive effects are determinants of the relationships: the Raoult effect, where dissolution depresses the surface vapor pressure on the solution; and the Kelvin effect, where the surface vapor pressure on a curved liquid surface is higher than that on a corresponding flat surface. 
The supersaturation around a droplet in equilibrium with the ambient vapor is determined by the following equation (e.g., Rogers and Yau 1989), assuming that the dissolved amount of solutes in the droplet does not change:

$$
\begin{aligned}
& S_{\mathrm{w}}=\frac{A}{r_{\mathrm{w}}}-\frac{B r_{\mathrm{CN}}^{3}}{r_{\mathrm{w}}^{3}} ; \\
& A \approx \frac{3.3 \times 10^{-5}}{T}(\mathrm{~cm}) \text { and } B \approx \frac{4.3 v}{M_{\mathrm{CN}}}\left(\frac{4 \pi \rho_{\mathrm{CN}}}{3}\right),
\end{aligned}
$$

where $S_{\mathrm{w}}$ is the equilibrium supersaturation, $r_{\mathrm{w}}$ the droplet radius, and $T$ the skin temperature of the droplet; $r_{\mathrm{CN}}$ is the radius of the dry $\mathrm{CN}$ particle before dissolution; and $v, M_{\mathrm{CN}}$, and $\rho_{\mathrm{CN}}$ are the van 't Hoff factor (e.g., Low 1969), molecular weight, and density of the $\mathrm{CN}$ component, respectively. The $\mathrm{CN}$ particle is assumed to be composed of a single soluble ingredient that has been completely dissolved in the droplet. In Eq. 7 , there is a unique peak of the supersaturation $S_{\text {crit(w) }}$ under the condition that $\mathrm{d} S_{w} / \mathrm{d} r_{w}=0$,

$$
\begin{aligned}
& S_{\text {crit }(\mathrm{w})}=\frac{2 A}{3 r_{\text {crit(w) }}} ; \\
& r_{\text {crit }(\mathrm{w})}=\sqrt{\frac{3 B r_{\mathrm{CN}}^{3}}{A}},
\end{aligned}
$$

where $r_{\text {crit(w) }}$ is the critical radius of the droplet that matches $S_{\text {crit(w). }}$. Once the ambient supersaturation reaches approximately $S_{\text {crit(w) }}$, droplets with radii greater than $r_{\text {crit(w) }}$ can exist stably. The critical radius of $\mathrm{CN}$, $r_{\text {crit(CN) }}$, can also be determined uniquely:

$$
r_{\mathrm{crit}(\mathrm{CN})}=\left(\frac{4}{27} \frac{A^{3}}{B} \frac{1}{S_{\mathrm{crit}(\mathrm{w})}{ }^{2}}\right)^{1 / 3} .
$$

Equation 11 represents the critical radius of $\mathrm{CN}$ as a function of supersaturation. If the radius of $\mathrm{CN}$ is larger than $r_{\text {crit }(\mathrm{CN})}, \mathrm{CN}$ is activated as $\mathrm{CCN}$ and the formed droplet exists stably under the ambient supersaturation, in excess of $S_{\text {crit(w) }}$.

\section{Appendix 2: Future plans for improving IN parametrization \\ Deposition and condensation-freezing nucleation}

A common approach to measuring ambient IN is by counting the change in the number of ice particles in a sampled airmass for a series of air temperature or supersaturation measurements. DeMott et al. (2010) provided an equation for the activated IN number concentration as a function of both temperature and the number concentration of aerosol particles with diameters larger than $0.5 \mu \mathrm{m}$, by combining measurement data at multiple locations from the Arctic to the Amazon Basin. This equation is represented by

$$
n_{\mathrm{IN}, T_{k}}=a\left(273.16-T_{k}\right)^{b}\left(n_{a>0.5}\right)^{\left(c\left(273.16-T_{k}\right)+d\right)},
$$

where $a=0.594 \times 10^{-4}, b=3.33, c=0.0264$, and $d=$ 0.0033; $T_{k}$ is the cloud temperature (in Kelvin), $n_{a>0.5}$ is the number concentration (in $\mathrm{cm}^{-3}$ ) of aerosol particles with diameters larger than $0.5 \mu \mathrm{m}$, and $n_{\mathrm{IN}, T k}$ is the active IN number concentration $\left(\right.$ std $\left.\mathrm{L}^{-1}\right)$. This parametrization may cover all heterogeneous ice nucleation types (i.e., deposition nucleation, condensation-freezing nucleation, contact freezing, and immersion freezing) because it is based on measurement data under water saturation conditions. However, Demott et al. (2010) indicated that $n_{\mathrm{IN}, T k}$ corresponds to the maximum number concentration of ambient IN activated mostly through deposition nucleation, because deposition nucleation is the primary contributor in mixed-phase clouds at temperatures above $-35{ }^{\circ} \mathrm{C}$ (Phillips et al. 2008). The measurement data were sampled at a temperature range between -9 and $-35^{\circ} \mathrm{C}$.

Several issues need to be solved before implementation of the parametrization described by Eq. 12 into a model coupled with the ALICIS module. Equation 12 can be interpreted in several ways in terms of how to connect the maximum number concentration of ambient IN at a given temperature to the number growth rate of cloud ice particles in a microphysics scheme. An approach described by Khain et al. (2000) can be appropriated to deal with this problem. A possible assumption is that new IN activation occurs only if the temperature decreases at a certain grid point. The number concentration of newly activated IN per time interval is given in a differential form:

$$
\begin{aligned}
& \frac{\mathrm{d} n_{\mathrm{IN}}}{\mathrm{d} t}=\left\{\begin{array}{cc}
-\frac{\mathrm{d} n_{\mathrm{IN}} \frac{\mathrm{d} T}{\mathrm{~d} T},}{\mathrm{~d} t}, & \text { if } \mathrm{d} T / \mathrm{d} t \leq 0 \\
0, & \text { if } \mathrm{d} T / \mathrm{d} t>0
\end{array} ;\right. \\
& \frac{\mathrm{d} T}{\mathrm{~d} t}=\left(\frac{\partial T}{\partial t}+u \frac{\partial T}{\partial x}+v \frac{\partial T}{\partial y}+w \frac{\partial T}{\partial z}\right),
\end{aligned}
$$

where $u, v$, and $w$ are the wind velocities in the framework of the three-dimensional Cartesian coordinates $x$, $y$, and $z$, respectively. The number of newly activated IN is directly applied to that of newly generated cloud ice particles.

Another problem is how to connect $n_{a>0.5}$ in Eq. 12 to the predicted size distribution spectra of aerosol in a model coupled with the ALICIS module. Sulfate, black carbon, organic, dust, and sea salt aerosols were assumed in the global model simulations of Demott et al. (2010); they predicted aerosol mass and number concentrations for the three specific modes in particle size for each aerosol species. The term $n_{a>0.5}$ in Eq. 12 was 
directly calculated from the size distribution of the four aerosol species, except for sea salt. A similar approach can be employed in a model coupled with the ALICIS module; $n_{a>0.5}$ can be calculated from the predicted size distribution spectra of the same four aerosol species. Depletion of IN is represented by reducing the number concentration of aerosol particles with diameters larger than $0.5 \mu \mathrm{m}$. The priority (i.e., what type and size of aerosol particles are preferentially activated) was not discussed by Demott et al. (2010). At present, larger aerosol particles are preferentially consumed; the type dependence is determined arbitrarily.

\section{Contact freezing}

Unlike deposition and condensation-freezing nucleation, contact freezing has hardly been fully parametrized or modeled in earlier atmospheric models. It is difficult to obtain appropriate measurement data to construct a parametrization scheme or an empirical formula. Lohmann and Diehl (2006) employed a parametrization based on Levkov et al. (1992) to calculate the contact-freezing probability only through Brownian diffusion of aerosol particles in their global aerosol transport model with bulk cloud microphysics. The freezing rate $Q_{\text {frz,cnt }}\left(\right.$ in $\mathrm{m}^{-3} \mathrm{~s}^{-1}$ ) is given by

$$
\begin{aligned}
& Q_{\mathrm{frz}, \mathrm{cnt}}=m_{i} D_{\mathrm{ap}} 4 \pi r_{w} N_{\mathrm{a}, \mathrm{cnt}} \frac{N_{w}{ }^{2}}{\rho q_{w}}, \\
& D_{\mathrm{ap}}=\frac{k T C_{\mathrm{c}}}{6 \pi \eta r_{\mathrm{am}}},
\end{aligned}
$$

where $m_{\mathrm{i}}$ is the mass of the newly formed ice particle through contact freezing, $D_{\text {ap }}$ is the Brownian aerosol diffusivity, $r_{\mathrm{w}}$ is the volume mean radius of the ambient supercooled droplets, $N_{\mathrm{a}, \mathrm{cnt}}$ is the number concentration of aerosol particles that can be activated as contact freezing nuclei at the relevant temperature, $N_{\mathrm{w}}$ is the number concentration of the supercooled droplets, $q_{\mathrm{w}}$ is the mass-mixing ratio of the supercooled droplets, $\rho$ is the air density, $k$ is the Boltzmann constant, $C_{\mathrm{c}}$ the Cunningham correction factor, $\eta$ the viscosity of air, and $r_{\mathrm{am}}$ the mode radius of the aerosol particles.

$N_{\mathrm{a}, \mathrm{cnt}}$ is the most important parameter for determining the efficiency of contact freezing in Eq. 15. Lohmann and Diehl (2006) assumed that hydrophilic black carbon and accumulation-mode dust particles were able to work as contact freezing nuclei; the activation probability was dependent on the particle composition and size, and on the temperature (see their Fig. 1). Dust aerosol particles can work as contact freezing nuclei at higher temperatures than black carbonaceous aerosol particles. If mineral dust particles are composed of montmorillonite, the onset temperature of contact freezing is approximately $-3{ }^{\circ} \mathrm{C}$; all dust particles can work as contact freezing nuclei at $-8{ }^{\circ} \mathrm{C}$. The onset temperature of contact freezing mediated by black carbonaceous particles is approximately $-10{ }^{\circ} \mathrm{C}$; the probability of freezing is largely dependent on the particle size.

This parametrization can be implemented in a model coupled with the ALICIS module without major modifications. If SBM is employed in the model, Eq. 15 is applied to all combinations between supercooled droplet bins and aerosol bins, on a one-by-one basis. On the other hand, if bulk cloud microphysics is employed, Eq. 15 directly provides the production rates of the mass-mixing ratio and the number concentration of cloud ice formed through contact freezing, as described by Lohmann and Diehl (2006).

\section{Immersion freezing}

Some prior studies already developed several empirical parametrization schemes to calculate immersion freezing rates under conditions that the particle composition and concentration of immersion freezing nuclei inside supercooled droplets are specified (e.g., Diehl and Wurzler 2004). However, the present SBM coupled with the ALICIS module does not explicitly predict the concentration or composition of impurities that potentially act as immersion freezing nuclei inside supercooled droplets. Accordingly, the present model needs to adopt an empirical parametrization that excludes the detailed characteristics of immersion freezing nuclei. As an alternative approach, Lohmann and Diehl (2006) employed the assumption that the concentration of potential IN inside supercooled droplets was identical to that in ambient air (i.e., aerosol particle concentration). Similarly, Fan et al. (2014) employed a parametrization that included a mineral dust aerosol concentration with particle diameters larger than $0.5 \mu \mathrm{m}$ (Tobo et al. 2013; DeMott et al. 2015). These approaches are still affected by large uncertainties, even though the ambient aerosol concentration is related to the number of activatable immersion IN inside supercooled droplets through wet scavenging.

\footnotetext{
Abbreviations

ABC: Atmospheric Brown Clouds; ABC-EAREX: Atmospheric Brown CloudEast Asian Regional Experiment; ACE-Asia: Asian Pacific Regional Aerosol Characterization Experiment; AEROCOM: Aerosol Comparisons between Observations and Models; AERONET: AErosol RObotic NETwork;

AGCM: atmospheric general circulation model; ALICIS: Aerosol Loading Interface for Cloud microphysics In Simulation; APEX-E3: 3rd Experiment of the Asian Atmospheric Particulate Environment Change Studies; ARM: Atmospheric Radiation Measurement; AVHRR: (space-borne) Advanced Very High Resolution Radiometer; CCN: cloud condensation nuclei; CDNC: cloud droplet number concentration; CN: condensation nuclei; CRM: cloud resolving model; DOE: Department of Energy;

DRAGON: Distributed Regional Aerosol Gridded Observation Networks; GEOS: NASA Goddard Earth Observing System model; GOCART: Goddard Chemistry Aerosol Radiation and Transport model; HadGEM: Hadley Centre Global Environment Model; HUCM: Hebrew University Cloud Model; IN: iceforming nuclei; INDOEX: INDian Ocean EXperiment; JMA-NHM: Japan
} 
Meteorological Agency Non-Hydrostatic Model; MERRAero: Modern Era Retrospective analysis for Research and Applications Aerosol Reanalysis; MODIS: Modulate Resolution Imaging Spectroradiometer; MOUDI: MicroOrifice Uniform Deposit Impactor; NASA: National Aeronautics and Space Administration; NU-WRF: NASA Unified WRF; SBM: spectral bin microphysics; SPRINTARS: Spectral Radiation Transport model for Aerosol Species; WRF: Weather Research and Forecasting model; WRF-Chem: Weather Research and Forecasting model coupled with chemistry; WRF-SBM: WRF coupled with HUCM SBM.

\section{Competing interests}

The authors declare that they have no competing interests.

\section{Authors' contributions}

$\mathrm{TI}$ proposed and designed the study and wrote most parts of the paper. IC and YS substantially contributed to writing the subsections of "Update by Choi et al. (2014): Aerosol particle size distribution revision and type multiplication" and "Update by Sato et al. (2012): Aerosol emission from evaporated cloud droplets," respectively. KS and TN collaborated with the other authors in the context of manuscript composition. All authors read and approved submission of the final manuscript.

\section{Acknowledgements}

This research was supported by the Global Environment Research Fund B-4 of the Ministry of Environment, Japan, by project RR2002 and the Data Integration for Earth Observation project of the Japanese Ministry of Education, Sports, Science, Culture, and Technology (MEXT). YS was supported by a Grant-in-Aid for JSPS Fellows (22-7893). IC was supported by the research and development project on the development of global numerical prediction systems of the Korea Institute of Atmospheric Prediction Systems (KIAPS), funded by the Korea Meteorological Administration (KMA). The authors thank the two anonymous reviewers and the journal editor for their helpful comments in improving this paper.

\section{Author details}

${ }^{1}$ Earth System Science Interdisciplinary Center, University of Maryland, College Park, MD, USA. ${ }^{2}$ Code 612 NASA Goddard Space Flight Center, Greenbelt, MD, USA. ${ }^{3}$ Korea Institute of Atmospheric Prediction Systems, Seoul, Republic of Korea. ${ }^{4}$ RIKEN Advanced Institute for Computational Science, Kobe, Japan. ${ }^{5}$ Atmosphere and Ocean Research Institute, The University of Tokyo, Kashiwa, Japan. ${ }^{6}$ Earth Observing Research Center, Japan Aerospace Exploration Agency, Tsukuba, Japan.

Received: 30 June 2015 Accepted: 7 December 2015 Published online: 11 December 2015

\section{References}

Abdul-Razzak H, Ghan SJ, Rivera-Carpio C. A parameterization of aerosol activation 1. Single aerosol type. J Geophys Res. 1998;103(D6):6123-31.

Abdul-Razzak H, Ghan SJ. A parameterization of aerosol activation 2. Multiple aerosol types. J Geophys Res. 2000;105(D5):6837-44.

Abdul-Razzak H, Ghan SJ. A parameterization of aerosol activation 3. Sectional representation. J Geophys Res. 2002;107(D3):4026. doi:10.1029/2001JD000483.

Ackerman AS, Toon OB, Stevens DE, Heymsfield AJ, Ramanathan V, Welton EJ. Reduction of tropical cloudiness by soot. Science. 2000;288:1042-7. doi:10. 1126/science.288.5468.1042

Adhikari M, Ishizaka Y, Minda H, Kazaoka R, Jensen JB, Gras JL, et al. Vertical distribution of cloud condensation nuclei concentrations and their effect on microphysical properties of clouds over the sea near the southwest islands of Japan. J Geophys Res. 2005;110:D10203. doi:10.1029/2004JD004758.

Albrecht BA. Aerosols, cloud microphysics, and fractional cloudiness. Science. 1989;245:1227-30.

Bellouin N, Rae J, Jones A, Johnson C, Haywood J, Boucher O. Aerosol forcing in the Climate Model Intercomparison Project (CMIP5) simulations by HadGEM2-ES and the role of ammonium nitrate. J Geophys Res. 2011;116: D20206. doi:10.1029/2011JD016074.

Bigg EK. The supercooling of water. Proc Phys Soc London. 1953;66B:688-94. doi: 10.1088/0370-1301/66/8/309.

Brechtel FJ, Kreidenweis SM, Swan HB. Air mass characteristics, total particle concentration, and size distributions at Macquarie Island, Tasmania, during the First Aerosol Characterization Experiment (ACE 1). J Geophys Res. 1998; 103:16,351-67. doi:10.1029/97JD03014.
Chen JP, Lamb D. Simulation of cloud microphysical and chemical processes using a multicomponent framework. Part I: description of the microphysical model. J Atmos Sci. 1994;51:2613-30. doi:10.1175/1520-0469(1994)051<2613:SOCMAC>2.0.CO;2.

Chin M, Ginoux P, Kinne S, Holben BN, Duncan BN, Martin RV, et al. Tropospheric aerosol optical thickness from the GOCART model and comparisons with satellite and sunphotometer measurements. J Atmos Sci. 2002;59:461-83.

Choi I-J, Iguchi T, Kim S-W, Nakajima T, Yoon S-C. The effect of aerosol representation on cloud microphysical properties in northeast Asia. Meteorol Atmos Phys. 2014;123:181-94. doi:10.1007/s00703-013-0288-y.

Chuang CC, Penner JE, Taylor KE, Grossman AS, Walton JJ. An assessment of the radiative effects of anthropogenic sulfate. J Geophys Res. 1997;102:3761-78.

Colarco P, da Silva A, Chin M, Diehl T. Online simulations of global aerosol distributions in the NASA GEOS-4 model and comparisons to satellite and ground-based aerosol optical depth. J Geophys Res. 2010;115:D14207. doi:10.1029/2009JD012820.

d'Almeida GA, Koepk P, Shettle EP. Atmospheric aerosols: global climatology and radiative characteristics. Hampton: A. Deepak Publishing; 1991. p. 561.

DeMott PJ, Prenni AJ, Liu X, Petters MD, Twohy CH, Richardson MS, et al. Predicting global atmospheric ice nuclei distributions and their impacts on climate. Proc Natl Acad Sci. 2010;107:11217-22.

DeMott PJ, Prenni AJ, McMeeking GR, Sullivan RC, Petters MD, Tobo Y, et al. Integrating laboratory and field data qualify the immersion freezing ice nucleation activity of mineral dust particles. Atmos Chem Phys. 2015;15:393409. doi:10.5194/acp-15-393-2015.

Diehl K, Wurzler S. Heterogeneous drop freezing in the immersion mode: Model calculations considering soluble and insoluble particles in the drops. J Atmos Sci. 2004;61:2063-72

Eck TF, Holben BN, Reid JS, Arola A, Ferrare RA, Hostetler CA, et al. Observations of rapid aerosol optical depth enhancements in the vicinity of polluted cumulus clouds. Atmos Chem Phys. 2012;14:11633-56. doi:10.5194/acp-1411633-2014.

Fan J, Leung LR, Li Z, Morrison H, Chen H, Zhou Y, et al. Aerosol impacts on clouds and precipitation in eastern China: results from bin and bulk microphysics. J Geophys Res. 2012;117:D00K36. doi:10.1029/2011JD016537.

Fan J, Leung LR, DeMott PJ, Comstock JM, Singh B, Rosenfeld D, et al. Aerosol impacts on California winter clouds and precipitation during CalWater 2011: local pollution versus long-range transport dust. Atmos Chem Phys. 2014;14: 81-101. doi:10.5194/acp-14-81-2014.

Feingold G, Kreidenweis SM, Stevens B, Cotton WR. Numerical simulations of stratocumulus processing of cloud condensation nuclei through collisioncoalescence. J Geophys Res. 1996;101(D16):21,391-402.

Feingold G, Cotton WR, Kreidenweis SM, Davis JT. The impact of giant condensation nuclei on drizzle formation in stratocumulus: implications for cloud radiative properties. J Atmos Sci. 1999;56:4100-17. doi:10.1175/ 1520-0469(1999)056<4100:TIOGCC>2.0.CO;2.

Formenti P, Schütz L, Balkanski Y, Desboeufs K, Ebert M, Kandler K, et al. Recent progress in understanding physical and chemical properties of African and Asian mineral dust. Atmos Chem Phys. 2011;11:8231-56. doi:10.5194/acp-11-8231-2011.

Fu Q, Thorsen TJ, Su J, Ge JM, Huang JP. Test of Mie-based single-scattering properties of non-spherical dust aerosols in radiative flux calculations. J Quant Spectrosc Radiat Transf. 2009;110:1640-53.

Geresdi I, Rasmussen R. Freezing drizzle formation in stably stratified layer clouds. Part II: the role of giant nuclei and aerosol particle size distribution and solubility. J Atmos Sci. 2005;62:2037-57.

Ghan SJ, Chang CC, Penner JE. A parameterization of cloud droplet nucleation, I, single aerosol type. Atmos Res. 1993;30:197-221.

Ghan S, Laulainen N, Easter R, Wagener R, Nemesure S, Chapman E, et al. Evaluation of aerosol direct radiative forcing in MIRAGE. J Geophys Res. 2001; 106(D6):5295-316. doi:10.1029/2000JD900502.

Ginoux P, Chin M, Tegen I, Prospero JM, Holben B, Dubovik O, et al. Sources and distributions of dust aerosols simulated with the GOCART model. J Geophys Res. 2001;106:20 255-73. doi:10.1029/2000JD000053.

Goto D, Nakajima T, Dai T, Takemura T, Kajino M, Matsui H, et al. An evaluation of simulated particulate sulfate over East Asia through global model intercomparison. J Geophys Res. 2015;120:6247-70. doi:10.1002/2014JD021693.

Grell GA, Peckham SE, Schmitz R, McKeen SA, Frost G, Skamarock WC, et al. Fully coupled 'online' chemistry in the WRF model. Atmos Environ. 2005;39:6957-76.

Hashino T, Tripori GJ. The spectral ice habit prediction system (SHIPS). Part I: model description and simulation of the vapor deposition process. J Atmos Sci. 2007;64:2210-37. 
Haywood JM, Roberts DL, Slingo A, Edwards JM, Shine KP. General circulation model calculations of the direct radiative forcing by anthropogenic sulfate and fossil-fuel soot aerosol. J Climate. 1997;10:1562-77.

Herzog M, Weisenstein DK, Penner JE. A dynamic aerosol module for global chemical transport models: model description. J Geophys Res. 2004;109: D18202. doi:10.1029/2003JD004405.

Holben BN et al. AERONET - a federated instrument network and data archive for aerosol characterization. Remote Sens Environ. 1998:66:1-16.

Huebert BJ, Bates T, Russell PB, Shi G, Kim YJ, Kawamura K, et al. An overview of ACE-Asia: strategies for quantifying the relationships between Asian aerosols and their climatic impacts. J Geophys Res. 2003;108(D23):8633. doi:10.1029/2003JD003550.

Iguchi T, Nakajima T, Khain AP, Saito K, Takemura T, Suzuki K. Modeling the influence of aerosols on cloud microphysical properties in the east Asia region using a mesoscale model coupled with a bin-based cloud microphysics scheme. J Geophys Res. 2008;113:D14215. doi:10.1029/ 2007JD009774.

Iguchi T, Matsui T, Shi JJ, Tao W-K, Khain AP, Hou A, et al. Numerical analysis using WRF-SBM for the cloud microphysical structures in the C3VP field campaign: impacts of supercooled droplets and resultant riming on snow microphysics. J Geophys Res. 2012a;117:D23206. doi:10.1029/2012JD018101.

Iguchi T, Matsui T, Tokay A, Kollias P, Tao W-K. Two distinct modes in one-day rainfall event during MC3E field campaign: analyses of disdrometer observations and WRF-SBM simulation. Geophys Res Let. 2012b;39:L24805. doi:10.1029/2012GL053329.

Iguchi T, Matsui T, Tao W, Khain A, Phillips V, Kidd C, et al. WRF-SBM simulations of melting layer structure in mixedphase precipitation events observed during LPVEX. J Appl Meteor Climatol. 2014;53:2710-31. doi:10.1175/JAMC-D-13-0334.1.

Ishizaka Y. Report of aircraft observations during APEX campaigns (in Japanese), report, Hydrospheric Atmos. Res. Cent. Nagoya, Japan: Nagoya University; 2004. p. 82.

Jacobson MZ. Investigating cloud absorption effects: global absorption properties of black carbon, tar balls, and soil dust in clouds and aerosols. J Geophys Res. 2012;117:D06205. doi:10.1029/2011JD017218.

Khain AP, Sednev I. Simulation of precipitation formation in the eastern Mediterranean coastal zone using a spectral microphysics cloud ensemble model. Atmos Res. 1996;43:77-110. doi:10.1016/S0169-8095(96)00005-1.

Khain AP, Pokrovsky A, Sednev I. Some effects of cloud-aerosol interaction on cloud microphysics structure and precipitation formation: numerical experiments with a spectral microphysics cloud ensemble model. Atmos Res. 1999;52:195-220. doi:10.1016/S0169-8095(99)00027-7.

Khain AP, Ovtchinnikov M, Pinsky M, Pokrovsky A, Krugliak H. Notes on the stateof-the-art numerical modeling of cloud microphysics. Atmos Res. 2000;55: 159-224. doi:10.1016/S0169-8095(00)00064-8.

Khain A, Lynn B, Dudhia J. Aerosol effects on intensity of landfalling hurricanes as seen from simulations with the WRF model with spectral bin microphysics. J Atmos Sci. 2010;67(2):365-84.

Khain AP, Beheng KD, Heymsfield A, Korolev A, Krichak SO, Levin Z, et al. Representation of microphysical processes in cloud-resolving models: spectral (bin) microphysics vs. bulk parameterization. Rev Geophys. 2015;53: 247-322. doi:10.1002/2014RG000468.

Kinne $S$ et al. An AeroCom initial assessment-optical properties in aerosol component modules of global models. Atmos Chem Phys. 2006;6:1815-34 doi:10.5194/acp-6-1815-2006.

Kogan YL. The simulation of a convective cloud in a 3-D model with explicit microphysics. Part I: model description and sensitivity experiments. J Atmos Sci. 1991;48:1160-89. doi:10.1175/1520-0469(1991)048<1160: TSOACC $>2.0 . \mathrm{CO} ; 2$.

Köhler $\mathrm{H}$. The nucleus in and the growth of hygroscopic droplets. Trans Faraday Soc. 1936;32:1152-61. doi:10.1039/tf9363201152.

Koop T, Luo BP, Tsias A, Peter T. Water activity as the determinant for homogeneous ice nucleation in aqueous solutions. Nature. 2000;406:611-4. doi:10.1038/35020537.

Kuba N, Fujiyoshi Y. Development of a cloud microphysical model and parameterizations to describe the effect of CCN on warm cloud. Atmos Chem Phy. 2006;6:2793-810

Laaksonen A, Korhonen P, Kulumala M, Charlson RJ. Modification of the Köhler equation to include soluble trace gases and slightly soluble substances. J Atmos Sci. 1998;55:853-62.

Levin Z, Cotton WR. Aerosol pollution impact on precipitation: a scientific review. Springer Science \& Business Media. 2008.
Levkov L, Rockel B, Kapitza H, Raschke E. 3D mesoscale numerical studies of cirrus and stratus clouds by their time and space evolution. Beitr Phys Atmos. 1992; 65:35-58.

Li G, Wang Y, Zhang R. Implementation of a two-moment bulk microphysics scheme to the WRF model to investigate aerosol-cloud interaction. J Geophys Res. 2008;113:D15211. doi:10.1029/2007JD009361.

Liu Y, Daum PH. Parameterization of the autoconversion process. Part I: analytical formulation of the Kessler-type parameterizations. J Atmos Sci. 2004;61:1539-48

Lohmann U, Diehl K. Sensitivity studies of the importance ofdust ice nuclei for the indirect aerosol effect on stratiform mixed-phase clouds. J Atmos Sci. 2006;63:968-82.

Lohmann U, Stier P, Hoose C, Ferrachat S, Kloster S, Roeckner E, et al. Cloud microphysics and aerosol indirect effects in the global climate model ECHAM5-HAM. Atmos Chem Phys. 2007;7:3425-46. doi:10.5194/acp-7-3425-2007.

Low RDH. A generalized equation for the solution effect in droplet growth. J Atmos Sci. 1969;26:608-11. doi:10.1175/1520-0469(1969)026<0608: AGEFTS>2.0.CO;2.

Lynn BH, Khain AP, Dudhia J, Rosenfeld D, Pokrovsky A, Seifert A. Spectral (bin) microphysics coupled with a mesoscale model (MM5). Part I: model description and first results. Mon Weather Rev. 2005a;133(1):44. doi:10.1175/MWR-2840.1

Lynn BH, Khain AP, Dudhia J, Rosenfeld D, Pokrovsky A, Seifert A. Spectral (bin) microphysics coupled with a mesoscale model (MM5). Part II: simulation of a CaPE rain event with a squall line. Mon Weather Rev. 2005b;133(1):59. doi:10.1175/MWR-2841.1.

Marenco F, Amiridis V, Marinou E, Tsekeri A, Pelon J. Airborne verification of CALIPSO products over the Amazon: a case study of daytime observations in a complex atmospheric scene. Atmos Chem Phys. 2014;14:11871-81. doi:10.5194/acp-14-11871-2014

Misumi R, Hashimoto A, Murakami M, Kuba N, Orikasa N, Saito A, et al. Microphysical structure of a developing convective snow cloud simulated by an improved version of the multi-dimensional bin model. Atmos Sci Let. 2010;11:186-91. doi:10.1002/asl.268.

Mitra SK, Brinkmann J, Pruppacher HR. A wind tunnel study on the drop-toparticle conversion. J Aerosol Sci. 1992;23:245-56.

Mochida M, Umemoto N, Kawamura K, Lim H-J, Turpin BJ. Bimodal size distributions of various organic acids and fatty acids in the marine atmosphere: influence of anthropogenic aerosols, Asian dusts, and sea spray off the coast of East Asia. J Geophys Res. 2007;112(15):D15209. doi:10.1029/2006JD007773.

Morrison H, Curry JA, Khvorostyanov VI. A new double-moment microphysics scheme for application in cloud and climate models. Part I: description. J Atmos Sci. 2005;62:1665-77.

Morrison H, Grabowski WW. Comparison of bulk and bin warm-rain microphysics models using a kinematic framework. J Atmos Sci. 2007;64:2839-61.

Morrison $\mathrm{H}$, Gettelman A. A new two-moment bulk stratiform cloud microphysics scheme in the community atmosphere model, version 3 (CAM3). Part l: description and numerical tests. J Climate. 2008;21:3642-59. doi:10.1175/2008JCLI2105.1.

Muhlbauer A, Lohmann U. Sensitivity studies of aerosol-cloud interactions in mixed-phase orographic precipitation. J Atmos Sci. 2009;66:2517-38.

Nakajima TY, Nakajima T. Wide-area determination of cloud microphysical properties from NOAA AVHRR measurements for FIRE and ASTEX regions. J Atmos Sci. 1995;52:4043-59. doi:10.1175/1520-0469(1995)052<4043: WADOCM>2.0.CO;2.

Nakajima T, Higurashi A, Kawamoto K, Penner JE. A possible correlation between satellite-derived cloud and aerosol microphysical parameters. Geophys Res Let. 2001;28:1171-4.

Nakajima TY, Uchiyama A, Takamura T, Tsujioka N, Takemura T, Nakajima T. Comparisons of warm cloud properties obtained from satellite, ground, and aircraft measurements during APEX intensive observation period in 2000 and 2001. J Meteorol Soc Jpn. 2005;83:1085-95. doi:10.2151/jmsj.83.1085.

Nakajima T et al. Overview of the Atmospheric Brown Cloud East Asian Regional Experiment 2005 and a study of the aerosol direct radiative forcing in east Asia. J Geophys Res. 2007;112:D24S91. doi:10.1029/2007JD009009.

Onishi R, Takahashi K. A warm-bin-cold-bulk hybrid cloud microphysical model. J Atmos Sci. 2012;69:1474-97. 
Park S, Bretherton CS, Rasch PJ. Integrating cloud processes in the Community Atmosphere Model, version 5. J Climate. 2014;27:6821-56. doi:10.1175/JCLI-D-14-00087.1.

Penner JE, Chuang CC, Grant K. Climate forcing by carbonaceous and sulfate aerosols. Clim Dynam. 1998;14:839-51.

Peters-Lidard CD, Kemp EM, Matsu T, Santanello Jr JA, Kumar SV, Jacob JP, et al. Integrated modeling of aerosol, cloud, precipitation and land processes at satellite-resolved scales. Environ Model Software. 2015;67:149-59. http://dx. doi.org/10.1016/j.envsoft.2015.01.007

Petters MD, Kreidenweis SM. A single parameter representation of hygroscopic growth and cloud condensation nucleus activity. Atmos Chem Phys. 2007; 7:1961-71.

Phillips VTJ, DeMott PJ, Andronache C. An empirical parameterization of heterogeneous ice nucleation for multiple chemical species of aerosol. J Atmos Sci. 2008;65:2757-83.

Phillips VTJ, Demott PJ, Andronache C, Pratt KA, Prather KA, Subramanian R, et al. Improvements to an empirical parameterization of heterogeneous ice nucleation and its comparison with observations. J Atmos Sci. 2013;70:378409. http://dx.doi.org/10.1175/JAS-D-12-080.1.

Pincus R, Baker MB. Effect of precipitation on the albedo susceptibility of clouds in the marine boundary layer. Nature. 1994;372:250-2. doi:10.1038/372250a0.

Pozzoli L, Janssens-Maenhout G, Diehl T, Bey I, Schultz MG, Feichter J, et al. Reanalysis of tropospheric sulfate aerosol and ozone for the period 1980-2005 using the aerosol-chemistry-climate model ECHAM5-HAMMOZ. Atmos Chem Phys. 2011;11:9563-94. doi:10.5194/acp-11-9563-2011.

Pruppacher HR, Klett JD. Microphysics of clouds and precipitation. Dordrecht, Netherlands: Kluwer Acad; 1997

Ramanathan $V$ et al. Indian Ocean Experiment: an integrated analysis of the climate forcing and effects of the great Indo-Asian haze. J Geophys Res. 2001:106(D22):28371-98. doi:10.1029/2001JD900133.

Ramanathan V, Ramana MV, Roberts G, Kim D, Corrigan C, Chung C, et al. Warning trends in Asia amplified by brown cloud solar absorption. Nature. 2007:448:575-8. doi:10.1038/nature06019.

Rasmussen RM, Geresdi I, Thompson G, Manning K, Karplus E. Freezing drizzle formation in stably stratified layer clouds: the role of radiative cooling of cloud droplets, cloud condensation nuclei, and ice initiation. J Atmos Sci. 2002;59:837-60

Roberts G, Nenes A. A continuous-flow stream-wise thermal gradient CCN chamber for atmospheric measurements. Aerosol Sci Technol. 2005;39:206-21.

Rogers RR, Yau MK. A short course in cloud physics. New York: Pergamon; 1989.

Rosenfeld D et al. Global observations of aerosol-cloud-precipitation-climate interactions. Rev Geophys. 2014;52:750-808.

doi:10.1002/2013RG000441.

Saito $\mathrm{K}$ et al. The operational JMA nonhydrostatic mesoscale model. Mon Weather Rev. 2006;134(4):1266. doi:10.1175/MWR3120.1.

Saleeby SM, Cotton WR. A large droplet mode and prognostic number concentration of cloud droplets in the Colorado State University Regional Atmospheric Modeling System (RAMS). Part I: module descriptions and supercell test simulations. J Appl Meteorol. 2004;43:182-95.

Saleeby SM, van den Heever SC. Developments in the CSU-RAMS aerosol model: emissions, nucleation, regeneration, deposition, and radiation. J Appl Meteor Climatol. 2013;52:2601-22. doi:10.1175/JAMC-D-12-0312.1.

Sato $Y$, Suzuki K, Iguchi T, Choi I-J, Kadowaki H, Nakajima T. Characteristics of correlation statistics between droplet radius and optical thickness of warm clouds simulated by a three-dimensional regional-scale spectral bin microphysics cloud model. J Atmos Sci. 2012;69:484-503. doi:10. 1175/JAS-D-11-076.1.

Sato Y. A numerical study on the microphysical properties of warm clouds off the west coast of California, CCSR report, vol. 49. Tokyo: The Univesity of Tokyo; 2012

Seifert A, Beheng KD. A two-moment cloud microphysics parameterization for mixed-phase clouds. Part 1: model description. Meteorol Atmos Phys. 2006; 92:45-66. doi:10.1007/s00703-005-0112-4.

Seiki T, Nakajima T. Aerosol effects of the condensation process on a convective cloud simulation. J Atmos Sci. 2014;71:833-53. doi:10.1175/JAS-D-12-0195.1

Seiki T, Kodama C, Noda AT, Satoh M. Improvement in global cloud-systemresolving simulations by using a double-moment bulk cloud microphysics scheme. J Climate. 2015;28:2405-19. doi:10.1175/JCLI-D-14-00241.1.

Shi JJ, Matsui T, Tao W-K, Tan Q, Peters-Lidard C, Chin M, et al. Implementation of an aerosol-cloud-microphysics-radiation coupling into the NASA unified
WRF: simulation results for the 6-7 August 2006 AMMA special observing period. Q J Roy Meteorol Soc. 2014;140:2158-75. doi:10.1002/qj.2286.

Shima S, Kusano K, Kawano A, Sugiyama T, Kawahara S. The super-droplet method for the numerical simulation of clouds and precipitation: a particlebased and probabilistic microphysics model coupled with a non-hydrostatic model. Q J Roy Meteorol Soc. 2009;135:1307-20. doi:10.1002/qj.441.

Skamarock WC, Kemp JB, Dudhia J, Gill DO, Barker DM, Wang W, et al. A description of the advanced research WRF version 2, NCAR Tech, NCAR Tech. Note NCAR/ TN-468+STR. Boulder, Colo: Natl. Cent. for Atmos. Res; 2005. p. 88.

Soong S-T, Ogura Y. A comparison between axisymmetric and slab-symmetric cumulus cloud models. J Atmos Sci. 1973:30:879-93.

Spracklen DV, Pringle KJ, Carslaw KS, Chipperfield MP, Mann GW. A global off-line model of size-resolved aerosol microphysics: I. Model development and prediction of aerosol properties. Atmos Chem Phys. 2005;5:2227-52.

Squires P. The micro-structure of cumuli in maritime and continental air. Tellus. 1956:8:443-4

Stokes GM, Schwartz SE. The Atmospheric Radiation Measurement (ARM) Program: programmatic background and design of the cloud and radiation test bed. Bull Am Meteorol Soc. 1994;75:1201-21. doi:10.1175/15200477(1994)075<1201:TARMPP>2.0.CO;2.

Storelvmo T, Kristjánsson JE, Ghan SJ, Kirkevåg A, Seland Ø, Iversen T. Predicting cloud droplet number concentration in Community Atmosphere Model (CAM)-Oslo. J Geophys Res. 2006;111:D24208. doi:10.1029/2005JD006300.

Storelvmo T, Kristjánsson JE, Lohmann U. Aerosol influence on mixed-phase clouds in CAM-Oslo. J Atmos Sci. 2008;65:3214-30.

Sullivan RC, Moore MJK, Petters MD, Kreidenweis SM, Roberts GC, Prather KA Effect of chemical mixing state on the hygroscopicity and cloud nucleation properties of calcium mineral dust particles. Atmos Chem Phys. 2009;9:3303-16.

Suzuki K, Nakajima T, Nakajima TY, Khain A. Correlation pattern between effective radius and optical thickness of water clouds simulated by a spectral bin microphysics cloud model. SOLA. 2006;2:116-9.

Suzuki K, Nakajima T, Satoh M, Tomita H, Takemura T, Nakajima TY, et al. Global cloud-system-resolving simulation of aerosol effect on warm clouds. Geophys Res Let. 2008;35:L19817. doi:10.1029/2008GL035449.

Suzuki K, Nakajima T, Nakajima TY, Khain AP. A study of microphysical mechanisms for correlation patterns between droplet radius and optical thickness of warm clouds with a spectral bin microphysics cloud model. J Atmos Sci. 2010;67:1126-41. doi:10.1175/2009JAS3283.1.

Takemura T, Okamoto H, Maruyama Y, Numaguti A, Higurashi A, Nakajima T. Global three-dimensional simulation of aerosol optical thickness distribution of various origins. J Geophys Res. 2000;105(D14):17,853-74. doi:10.1029/ 2000JD900265

Takemura T, Nakajima T, Dubovik O, Holben BN, Kinne S. Single-scattering albedo and radiative forcing of various aerosol species with a global three-dimensional model. J Climate. 2002;15:333-52.

Takemura T, Egashira M, Matsuzawa K, Ichijo H, O'ishi R, Abe-Ouchi A. A simulation of the global distribution and radiative forcing of soil dust aerosols at the Last Glacial Maximum. Atmos Chem Phys. 2009:9:3061-73.

Tao W-K, Simpson J, McCumber M. An ice-water saturation adjustment. Mon Weather Rev. 1989:117:231-5.

Tao W-K, Chen J-P, Li Z, Wang C, Zhang C. Impact of aerosols on convective clouds and precipitation. Rev Geophys. 2012;50:RG2001. doi:10.1029/2011RG000369.

Thompson G, Eidhammer T. A study of aerosol impacts on clouds and precipitation development in a large winter cyclone. J Atmos Sci. 2014;71: 3636-58. doi:10.1175/JAS-D-13-0305.1.

Tobo Y, Prenni AJ, DeMott PJ, Huffman JA, McCluskey CS, Tian G, et al. Biological aerosol particles as a key determinant of ice nuclei populations in a forest ecosystem. J Geophys Res. 2013;118:10100-10. doi:10.1002/jgrd.50801.

Twomey S. The nuclei of natural cloud formation: Part II. The supersaturation in natural clouds and the variation of cloud droplet concentration. Geofis Pura Appl. 1959b;43:243-9. doi:10.1007/BF01993560.

Twomey S. Pollution and the planetary albedo. Atmos Environ. 1974;8:1251-6.

Twomey S. The influence of pollution on the shortwave albedo of clouds. J Atmos Sci. 1977;34:1149-52.

Twomey SA, Piepgrass M, Wolfe TL. An assessment of the impact of pollution on global cloud albedo. Tellus B. 1984;36:5.

Vali G. Nucleation terminology. Bull Am Meteorol Soc. 1985;66:1426-7.

Wang M, Ghan S, Ovchinnikov M, Liu X, Easter R, Kassianov E, et al. Aerosol indirect effects in a multi-scale aerosol-climate model PNNL-MMF. Atmos Chem Phys. 2011;11:5431-55. doi:10.5194/acp-11-5431-2011. 
Wang Y, Fan J, Zhang R, Leung LR, Franklin C. Improving bulk microphysics parameterizations in simulations of aerosol effects. J Geophys Res Atmos. 2013;118:5361-79. doi:10.1002/jgrd.50432.

Xue L, Teller A, Rasmussen R, Geresdi I, Pan Z. Effects of aerosol solubility and regeneration on warm-phase organic clouds and precipitation simulated by a detailed bin microphysical scheme. J Atmos Sci. 2010;67:3336-54. doi:10. 1175/2010JAS3511.1.

Yum SS, Roberts G, Kim JH, Song K, Kim D. Submicron aerosol size distributions and cloud condensation nuclei concentrations measured at Gosan, Korea, during the Atmospheric Brown Clouds-East Asian Regional Experiment 2005. J Geophys Res. 2007;112:D22S32. doi:10.1029/2006JD008212.

Yumimoto K, Takemura T. The SPRINTARS version 3.80/4D-Var data assimilation system: development and inversion experiments based on the observing system simulation experiment framework. Geosci Model Dev. 2013;6:2005-22. doi:10.5194/gmd-6-2005-2013.

Zhang K, Wan H, Wang B, Zhang M, Feichter J, Liu X. Tropospheric aerosol size distributions simulated by three online global aerosol models using the M7 microphysics module. Atmos Chem Phys. 2010;10:6409-34 doi:10.5194/acp-10-6409-2010.

\section{Submit your manuscript to a SpringerOpen ${ }^{\circ}$ journal and benefit from:}

- Convenient online submission

- Rigorous peer review

- Immediate publication on acceptance

- Open access: articles freely available online

- High visibility within the field

- Retaining the copyright to your article

Submit your next manuscript at $\boldsymbol{s p r i n g e r o p e n . c o m ~}$ 